\title{
Acquisition of Cholangiocarcinoma Traits during Advanced Hepatocellular Carcinoma Development in Mice
}

Liyuan Li, ${ }^{*}$ Maoxiang Qian, ${ }^{*}$ I-Hsuan Chen, ${ }^{\dagger}$ David Finkelstein, ${ }^{\ddagger}$ Arzu Onar-Thomas, ${ }^{\S}$ Melissa Johnson, ${ }^{\natural}$ Christopher Calabrese, Armita Bahrami, " Dolores H. López-Terrada, ${ }^{*}$ Jun J. Yang, ${ }^{*}$ W. Andy Tao, ${ }^{\dagger}$ and Liqin Zhu*

From the Departments of Pharmaceutical Sciences, ${ }^{*}$ Computational Biology, ${ }^{\ddagger}$ Statistics, ${ }^{\S}$ Small Animal Imaging Core,, and Pathology, ${ }^{\natural}$ St. Jude Children’s Research Hospital, Memphis, Tennessee; the Department of Biochemistry, ${ }^{\dagger}$ Purdue University, West Lafayette, Indiana; and the Department of Pathology, ${ }^{* *}$ Texas Children's Hospital and Baylor College of Medicine, Houston, Texas

\author{
Accepted for publication \\ November 21, 2017. \\ Address correspondence to \\ Liqin Zhu, Ph.D., Department \\ of Pharmaceutical Sciences, St. \\ Jude Children's Research \\ Hospital, 262 Danny Thomas \\ Place, Memphis, TN 38105- \\ 3678. E-mail: liqin.zhu@ \\ stjude.org.
}

\begin{abstract}
Past studies have identified hepatic tumors with mixed hepatocellular carcinoma (HCC) and cholangiocarcinoma (CC) characteristics that have a more aggressive behavior and a poorer prognosis than classic HCC. Whether this pathologic heterogeneity is due to a cell of origin of bipotent liver progenitors or the plasticity of cellular constituents comprising these tumors remains debated. In this study, we investigated the potential acquisition of CC-like traits during advanced development of HCC in mice. Primary and rare high-grade HCC developed in a genetic mouse model. A mouse model of highly efficient HCC invasion and metastasis by orthotopic transplantation of liver cancer organoids propagated from primary tumors in the genetic model was further developed. Invasive/metastatic tumors developed in both models closely recapitulated advanced human HCC and displayed a striking acquisition of CCrelated pathologic and molecular features, which was absent in the primary HCC tumors. Our study directly demonstrates the pathologic evolution of HCC during advanced tumor development, providing the first evidence that tumors with mixed HCC and CC features, or at least a subset of these tumors, represent a more advanced developmental stage of HCC. Finally, liver cancer organoid-generated highgrade tumors exhibited significantly increased extracellular vesicle secretion, suggesting that identifying tumor-specific extracellular vesicle proteins in plasma may be a promising tool for liver cancer detection. (Am J Pathol 2018, 188: 656-671; https://doi.org/10.1016/j.ajpath.2017.11.013)
\end{abstract}

Liver cancer is the sixth most common type of cancer and the second leading cause of cancer deaths worldwide. ${ }^{1}$ Hepatocellular carcinoma (HCC) and cholangiocarcinoma (CC) are the two major types of liver cancer in adults, with the former being much more common and pathologically heterogeneous than the latter. ${ }^{2,3}$ Past studies have identified HCC tumors with a CC-like gene expression pattern, as well as rare biphenotypic tumors with mixed $\mathrm{HCC}$ and $\mathrm{CC}$ pathology (combined HCC-CC, or CHC). These heterogeneous tumors often display more aggressive behaviors and have a poorer prognosis compared with those of classic HCC. ${ }^{4-6}$ Similar to $\mathrm{HCC}, \mathrm{CC}$ also exhibits pronounced pathologic heterogeneity in its patients, raising questions over the cell of origin of this extremely aggressive liver cancer type. ${ }^{7}$ Because of the difficulties in tracking the pathologic evolution of patient tumors, it remains difficult to determine by patient tumor characterization whether such a mixed CC and HCC pathology reflects a cellular origin of bipotential hepatic progenitor cells (HPCs) or is acquired by cell de- or trans-differentiation during tumor progression., In fact, oncogenic transformation of HPC populations in various mouse models have not yet produced hepatic tumors with $\mathrm{CHC}$ morphology, suggesting the wide spectrum of tumor heterogeneity found in human liver cancer patients

\footnotetext{
Supported by St. Jude Children's Research Hospital Comprehensive Cancer Center Developmental Funds Parent Grant P30 CA021765 (L.Z.) and NIH grants 5R01GM088317 and 5R01GM111788 (W.A.T.).

L.L. and M.Q. contributed equally to this work.

Disclosures: None declared.
} 
may, at least partially, result from tumor cell plasticity at an advanced stage.

Most liver cancers are diagnosed at advanced stage because of late presentation of disease-related symptoms. However, current liver cancer mouse models have largely recapitulated the early stages of liver cancer development and rarely focus on its aggressive forms. ${ }^{10,11}$ Accurate model systems that recapitulate late-stage human liver tumorigenesis are necessary to address the heterogeneity and plasticity of hepatic tumors in patients. Co-deletion of tumor suppressor genes Pten and Tp53 in a prominin-1 $\left(\right.$ Prom1) ${ }^{+}$HPC population in mice induces liver tumor formation with predominantly HCC pathology [Prom-

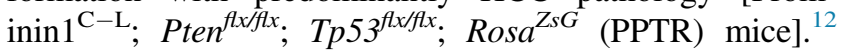
Local invasion and distant metastases with HCC morphology were identified in a small subset of the animals. This study aimed to dissect the histologic and molecular evolvement from the primary disease to the advanced invasive and metastatic tumors in this model with a particular focus on the potential acquisition of CC-like traits in the high-grade $(\mathrm{HG})$ tumors.

Because of the low frequencies of invasion and metastasis in this model, a novel approach was developed to model aggressive liver cancer development by orthotopic transplantation of liver cancer organoids (LCOs) propagated from PPTR primary tumors under liver stem cell culture condition. Past studies have suggested that a subset of cancer cells with stem cell-like properties, so called cancer stem cells (CSCs), are responsible for tumor progression, relapse, and metastasis across a wide range of cancers, including liver cancer. ${ }^{13-16}$ Indeed, an association between increased tumor cell stemness and poor prognosis has been widely observed in patients with liver cancer, which supports the hypothesis that advanced liver cancer development can be recapitulated with CSC-mediated models of liver cancer. ${ }^{4,13,17}$ However, conventional approaches to identify CSCs by using stem cell surface markers has yielded highly controversial results most likely because of tumor heterogeneity and plasticity, particularly at advanced stages. ${ }^{15,18,19}$ With rapid advances in three-dimensional (3D) stem cell cultures in recent years, cancer cells with the potential to develop into CSCs can now be readily enriched and propagated as cancer organoids. Indeed, cancer organoids derived from tumor specimens by in vitro 3D culture have been used to model tumorigenesis in a wide range of cancer types. ${ }^{20}$ Therefore, primary LCOs were cultivated from the PPTR primary tumors and established an LCO in vivo transplantation model to study advanced HCC development and particularly the morphologic and molecular evolution of liver cancer.

\section{Materials and Methods}

Mice

PPTR and Prominin $1^{\mathrm{C}-\mathrm{L}}$; Rosa ${ }^{\mathrm{NICD} 1 /+}$; Rosa ${ }^{Z s G}$ (PNR) genetic mouse models were previously reported. ${ }^{21} \mathrm{CD}-1$
NU/NU mice were purchased from Charles River Laboratories (Wilmington, MA). Full-body necropsies were performed on moribund mice, and tumor-bearing tissues were subjected to gross green fluorescent protein (GFP) microscopy with a SteREO DiscoveryV12 fluorescence stereomicroscope (Zeiss, Oberkochen, Germany). Paraffinembedded tissue sections $(4 \mu \mathrm{m})$ were subjected to direct GFP microscopy, hematoxylin and eosin staining, and immunostaining. Survival curves were calculated and plotted with GraphPad Prism software version 6.07 (GraphPad Software, Inc., San Diego, CA). All mice were maintained in a specific pathogen-free facility, and all animal experiments were performed in accordance with protocols approved by the Institutional Animal Care and Use Committee of St. Jude Children's Research Hospital.

\section{Liver Organoid Culture}

Single cells were isolated from liver tumor tissues with the use of papain digestion solution $[10 \mathrm{U} / \mathrm{mL}$ Papain (Worthington, Lakewood, NJ), $1 \mathrm{mmol} / \mathrm{L}$ N-acetyl cysteine (Sigma-Aldrich, St. Louis, MO), $12 \mu \mathrm{g} / \mathrm{mL}$ DNase I (Sigma-Aldrich) in Advanced Dulbecco's Modified Eagle Medium: Nutrient Mixture F-12 (Thermo Fisher Scientific, Waltham, MA)] and maintained in mouse liver stem cell culture conditions as previously reported. ${ }^{22}$ In brief, cells were suspended in Advanced Dulbecco's Modified Eagle Medium: Nutrient Mixture F-12 medium (Thermo Fisher Scientific) supplemented with $2 \%$ B27, $1 \%$ N2 (both from Thermo Fisher Scientific), 10\% Pen-Strep, and 10\% L-glutamine, and mixed with $50 \%$ Wnt 3 A conditioned media from L Wnt-3A cells (CRL-2647; ATCC, Manassas, VA) supplemented with $1.25 \mathrm{mmol} / \mathrm{L} \mathrm{N}$-acetyl cysteine (Sigma-Aldrich), $10 \mathrm{nmol} / \mathrm{L}$ Gastrin (Sigma-Aldrich), and growth factors, including $50 \mathrm{ng} / \mathrm{mL}$ epidermal growth factor (PeproTech, Rocky Hill, $\mathrm{NJ}), 1 \mu \mathrm{g} / \mathrm{mL}$ R-spondin1, $100 \mathrm{ng} / \mathrm{mL}$ Noggin, $100 \mathrm{ng} / \mathrm{mL}$ fibroblast growth factor (FGF)-10, $50 \mathrm{ng} / \mathrm{mL}$ hepatocyte growth factor (all from R\&D Systems, Minneapolis, MN), and $10 \mathrm{mmol} / \mathrm{L}$ Nicotinamide (Sigma-Aldrich). Cells were then seeded in 60-mm culture plates (Corning, Corning, NY) coated with growth factor-reduced Matrigel (Corning). Cells formed liver organoids after 3 days in culture. To passage, liver organoids were lifted from Matrigel with the use of dispase (Corning), collected with a $40-\mu \mathrm{m}$ cell strainer (Corning), and dissociated into single cells with the use of accutase (Thermo Fisher Scientific). Passaging was performed at a 1:3 ratio once every 5 to 7 days.

\section{Ultrasound-Guided Intrahepatic Cell Injection}

LCOs were dissociated from cultures with accutase (Thermo Fisher Scientific) and resuspended in 100\% Matrigel (Corning) at a concentration of 10,000 cells/ $\mu \mathrm{L}$. CD-1 NU/ NU mice (Charles River Laboratories) were injected under ultrasound guidance with $10 \mu \mathrm{L}$ of cell suspension into the median lobe of the liver at 2 months of age ( 1 injection per 
mouse). Mice were anesthetized with $2 \%$ to $3 \%$ isoflurane $/ \mathrm{O}_{2}$, positioned ventrally, and secured on the heated platform. Warmed Aquasonic 100 (Parker Laboratories, Fairfield, NJ) coupling gel was applied to the surface of the abdominal skin, and the right liver lobe was imaged with a VEVO-770 High Resolution Ultrasound system (FujiFilm VisualSonics, Toronto, ON, Canada). A 22-gauge catheter (BD Biosciences, Franklin Lakes, NJ) was inserted gently through the skin perpendicular to the incident plane of the transducer into the ultrasound field of view. The catheter needle was then removed to leave the plastic housing for injection. Cell suspension $(10 \mu \mathrm{L})$ was drawn with a precooled $50-\mu \mathrm{L}$ Hamilton syringe with a 27-gauge needle (Hamilton, Reno, $\mathrm{NV}$ ). The needle was then placed in the injector housing and guided into the right liver lobe within the ultrasonic field of view with the use of stereotactic controls. Cells were injected, and the needle was retained in situ for 1 minute to allow the implant to solidify. The needle was then slowly removed, followed by the gentle removal of the catheter. The animal was then removed from the bed and monitored until recovery.

\section{Quantification of Tumor Burden in LCO Recipient Mice}

Full-body necropsies were performed after euthanization of moribund LCO recipient mice. Mice with no signs of illness were euthanized by 12 months after transplantation. Gross organ GFP fluorescence was imaged by fluorescence stereomicroscopy. The area of $\mathrm{GFP}^{+}$tumors and the area of the total organ were calculated with AxioVision Rel. 4.8 (Zeiss). The burden of the local liver tumors and metastases were categorized as level 1 through 3 according to the ratio of the areas of $\mathrm{GFP}^{+}$tumors and the total organ (level $1<20 \%$; level $2=20 \%$ to $50 \%$; level $3>50 \%$ ).

\section{Antibodies}

Anti-Ki67 (VP-RM04; dilution 1:1000; Vector Laboratories, Burlingame, CA), anti-cytokeratin 19 (Ck19; ab133496; dilution 1:200; Abcam, Cambridge, MA), anti-Vimentin (ab92547; dilution 1:500; Abcam), anti-vascular cell adhesion molecule 1 (ab134047; dilution 1:1000; Abcam), antihepatocyte nuclear factor $4 \alpha$ (sc-6556; dilution 1:200; Santa Cruz Biotechnology, Dallas, TX); anti-epithelial cell adhesion molecule (EpCAM; ab32392; dilution 1:200; Abcam), and anti-SRY-related HMG-box (Sox)17 (AF1924; dilution 1:100; R\&D Systems) were used.

\section{RNA Sequencing}

Total RNA was extracted from mouse samples with the use of an Aurum Total RNA Mini Kit (Bio-Rad, Hercules, CA). Libraries for RNA sequencing (RNA-seq) samples were constructed with the TruSeq Stranded Total RNA Kit (Illumina, San Diego, CA) and sequenced on an Illumina HiSeq 2500. RNA-seq reads (100 bp paired-end) were aligned to the mouse genome (NCBI36/mm9) serially by Burrows-Wheeler Aligner (BWA) ${ }^{23}$ and STAR. ${ }^{24}$ Reads were counted by HTSeq, and FPKM (fragments per kilobase of transcript per million mapped reads) was $\log 2$ transformed as follows: $\log _{2} \mathrm{FPKM}=\log _{2}(\mathrm{FPKM}+2)$.

\section{Extracellular Vesicle Analysis by Mass Spectrometry}

Whole blood of control mice and LCO recipients was collected in blood collection tubes (BD Biosciences) and centrifuged at $1000 \times g$ at room temperature for 10 minutes. The supernatant was centrifuged again at $4000 \times g$ at room temperature for 15 minutes. The supernatant was collected as plasma. One milliliter of plasma was used for each biological replicate. To collect plasma extracellular vesicles (EVs), plasma was centrifuged at $20,000 \times g$ at $4^{\circ} \mathrm{C}$ for 1 hour. Pellets were washed with cold phosphate-buffered saline and centrifuged again at $20,000 \times g$ at $4^{\circ} \mathrm{C}$ for 1 hour. The pellets were collected as EVs and subjected to proteomic profiling by Easy-nLC 1000 liquid chromatography (Thermo Fisher Scientific) and a Velos Pro LTQ-Orbitrap mass spectrometer (Thermo Fisher Scientific). Data processing was performed as according to a previously reported protocol with some modifications. ${ }^{25}$ Raw files were cross-referenced to the mouse UniprotKB database with MaxQuant software version 1.5.4.1 (Max Planck Institute of Biochemistry, Munich, Germany) and Andromeda search engine. ${ }^{26}$ All data were analyzed with Perseus software version 1.5.4.1 (Max Planck Institute of Biochemistry). ${ }^{27}$ Significantly increased peptides in the EVs from LCO recipient mouse samples were identified by $t$-test with a permutation-based false discovery rate cutoff of 0.02 with $\mathrm{S}_{0}$ set at 0.5 .

\section{Unsupervised Gene Hierarchical Clustering, Principal Component Analysis, GSEA, and Gene Ontology Enrichment Analysis}

Genes identified by RNA-seq of all samples were ranked by mean absolute deviation score. The top genes with the mean absolute deviation scores $>1$ were imported into the Spotfire Decision Site for unsupervised hierarchical clustering (version 20.3.0.94; TIBCO Software Inc., Palo Alto, CA). Principal component analysis was performed with the function of prcomp in $\mathrm{R}$ version $\times 64$ 3.1.3 (R Foundation, Vienna, Austria). The first two principal components (PCs) explained $>82 \%$ of the total variance: $\mathrm{PC} 1$ with $53.6 \%$ and $\mathrm{PC} 2$ with $29.1 \%$. For Gene Set Enrichment Analysis (GSEA), mouse genes identified by RNA-seq of all samples were converted to the corresponding human homologous ones based on the HomoloGene database (build 68). GSEA was then performed with the online analytical resource from the Broad Institute (http://www.broadinstitute. org/gsea/index.jsp; last accessed October 13, 2017). For gene ontology enrichment analysis, genes with more than twofold increase between compared groups were analyzed with the online analytic tool Enrichr (http://amp.pharm.mssm.edu/ Enrichr; last accessed October 13, 2017). 


\section{KEGG Pathway Enrichment Analysis and Visualization}

KEGG pathway enrichment analyses were performed for the top 500 differentially expressed genes (LCO-driven tumors versus PPTR primary tumors) by using the $\mathrm{R}$ package clusterProfiler version 3.2.14 (R Foundation). ${ }^{28}$ Gene expression change in Wnt and Notch signaling pathways were visualized with $\mathrm{R}$ package Pathview version 1.14.0 (R Foundation). ${ }^{29}$

\section{Results}

Spontaneous HG Tumors in PPTR Mice Display Human Liver Cancer Gene Signatures Associated with Poor Prognosis and CC-Like Traits

Prom1 (also called CD133 in humans) is a liver stem cell marker. ${ }^{2,30}$ With the use of a previously generated Prom 1 knock-in mouse (Proml ${ }^{\text {CreERT2-LacZ }}$, or Proml $\left.{ }^{C-L}\right),{ }^{21}$ it was shown that Prom $1^{+}$cells are bipotent liver progenitors in the neonatal liver that participate in the development of both hepatocyte and cholangiocyte lineages (Figure 1A). Overexpression of Proml in mice with co-deletion of tumor suppressor genes Pten and Tp53 (PPTR mice) induced high rates of tumor formation with predominantly HCC pathology. ${ }^{12}$ Tumors in this model grew slowly, and only $6.7 \%$ of mice $(n=6 / 90)$ developed local invasion or metastases.

To characterize whether the invasive and metastatic tumors from PPTR mice (ie, HG-PPTR tumors) modeled advanced human HCC, the gene expression of five HGPPTR (three peritoneal invasions, one intrahepatic, and one pulmonary metastasis), 11 primary tumors (including the matched primary tumors for the five HG-PPTR tumors), and six tumor-adjacent liver tissues was profiled by RNA-seq (Supplemental Table S1) (https://www.ncbi.nlm.nih.gov/ geo/query/acc.cgi? acc = GSE94583; accession number GSE94583). Subsequent GSEA demonstrated an enrichment of multiple up-regulated and down-regulated gene sets that were associated with recurrence, metastasis, or poor prognosis of human HCC in the HG-PPTR
A

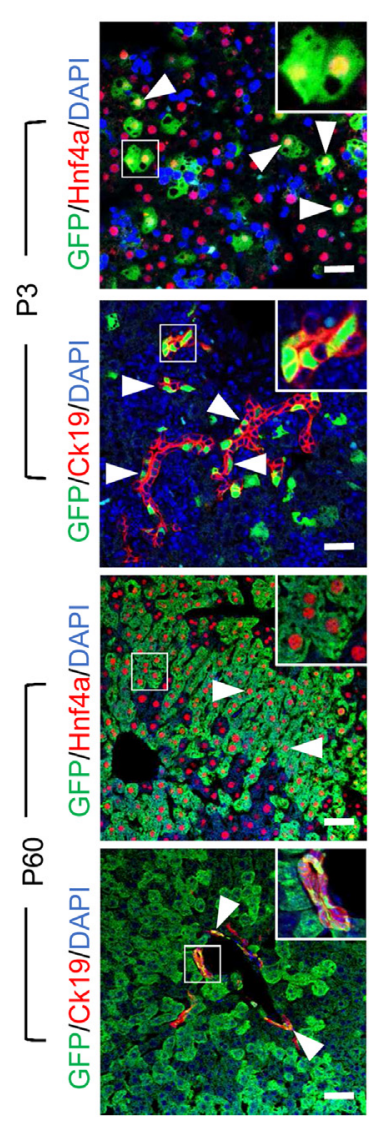

B

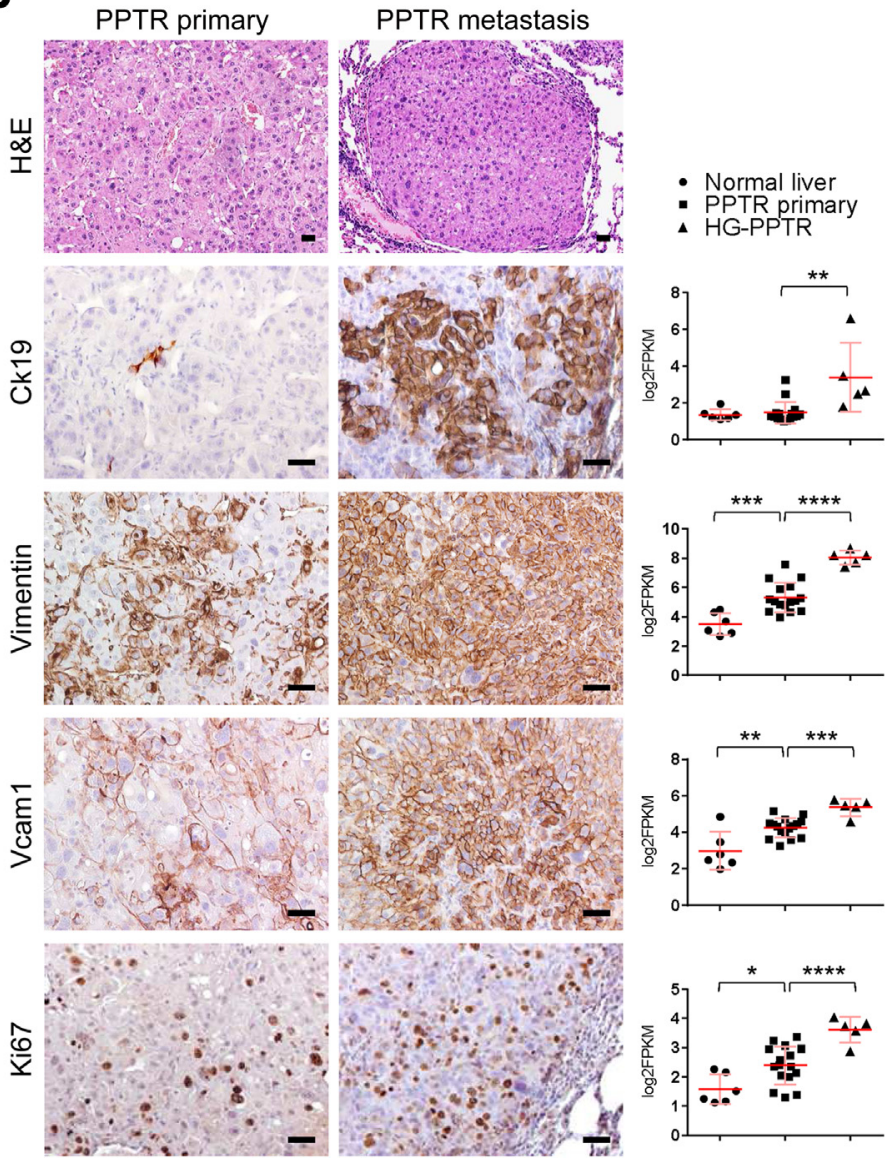

Figure 1 Prominin $1^{\mathrm{C}-\mathrm{L}} ; \operatorname{Pten}^{f l x / f(x} ; \operatorname{Tp} 53^{f(x / f l x} ; \operatorname{Ros}^{2 s G}$ (PPTR) mice develop rare high-grade (HG) tumors that resemble human hepatocellular carcinoma (HCC) with poor prognosis and enhanced cholangiocarcinoma (CC) traits. A: Co-immunofluorescence staining of green fluorescent protein (GFP) and hepatocyte marker hepatocyte nuclear factor $4 \alpha$ (Hnf4a) and cholangiocyte marker $\mathrm{Ck} 19$ in the liver of Prom $1^{\mathrm{C}-L /+}$; Rosa ${ }^{25 G /+}$ mice 1 day and 60 days after tamoxifen treatment. Arrows show $\mathrm{Hnf}_{4} \mathrm{a}^{+}$hepatocytes and $\mathrm{Ck} 19^{+}$cholangiocytes. Insets show higher-magnification images of the boxed areas. B: Hematoxylin and eosin (H\&E) staining, immunohistochemistry, and mRNA expression levels of the indicated biomarkers in primary and metastatic PPTR tumors. ${ }^{*} P<0.05,{ }^{* *} P<0.01,{ }^{* * *} P<0.001$, and ${ }^{* * * * P}<0.0001$ healthy liver or PPTR metastases versus PPTR primary tumors (unpaired $t$-tests). Scale bars: $50 \mu \mathrm{m}$. Original magnification, $\times 40$ (A, insets). FPKM, fragments per kilobase of transcript per million mapped reads; Vcam1, vascular cell adhesion molecule 1. 
tumors, compared with that of the primary tumors (Table 1). To validate the aggressive phenotype of the HG-PPTR tumors, the expression of multiple known markers of high-risk liver cancer, including $\mathrm{Ck} 19,{ }^{31}$ Vimentin, ${ }^{32}$ vascular cell adhesion molecule $1,^{33}$ and Ki67, was examined. ${ }^{34}$ RNA-seq and immunostaining confirmed upregulation of all genes in the HG-PPTR tumors, compared with that of the primary tumors at both RNA and protein levels (Figure 1B). Among the HCC gene sets enriched in the HG-PPTR tumors, two CC-like gene sets that were previously identified in a subset of human HCC tumors with poor prognosis showed high levels of enrichment, ${ }^{5}$ which strongly suggested an acquisition of the CC-like phenotype in PPTR mice during the spontaneous tumor progression from localized disease to advanced tumors. To further validate this pathologic and molecular evolution of HCC, a more efficient in vivo model system was generated to specifically recapitulate late-stage HCC invasion and metastasis.

\section{D Stem Cell Cultures Enable Rapid Propagation of Primary LCOs with Stem Cell Characteristics from Nonmetastatic PPTR Primary Tumors}

CSCs have been strongly implicated in the progression of advanced liver cancer. ${ }^{13,35,36}$ Indeed, RNA-seq detected considerable up-regulation of a number of liver stem cell markers in HG-PPTR tumors compared with those of the primary tumors, including EpCAM $,{ }^{37} \mathrm{Ck} 19,{ }^{2}$ intercellular adhesion molecule $1,{ }^{38} \operatorname{Sox} 9,{ }^{39} \mathrm{Cd} 24,{ }^{40} \mathrm{Cd} 44,{ }^{17}$ and $\alpha$ fetoprotein $^{41}$ (Figure 2B, Supplemental Figure S1). Most of these liver stem cell markers have already shown moderate increase in the PPTR primary tumors compared with tumoradjacent tissues. Other liver stem cell markers such as Prom $1 / \mathrm{Cd} 133,{ }^{2,30} \mathrm{Cd} 13,{ }^{42} \mathrm{Cd} 90,{ }^{43}$ Sal-like protein $4,{ }^{44}$ axis inhibition protein $2,{ }^{45}$ and leucine-rich repeat-containing Gprotein coupled receptor $5^{46}$ were relatively less altered (Supplemental Figure S1). Therefore, it was hypothesized that cancer cells with stemness properties capable of driving advanced disease were present but at low abundance in the primary tumors. To unbiasedly propagate stem-like tumor cells regardless of their expression of specific liver stem cell markers, as well as other tumor cells that have the potential to acquire similar stemness, cells were isolated from the primary tumors of five individual PPTR mice that did not develop advanced tumors, and the cells were maintained in serumfree, Matrigel-coated 3D liver stem cell culture conditions, as previously reported. ${ }^{22}$ Cells from all five tumors readily formed 3D organoids within 3 days in culture (named LCO1 to LCO5) and expressed GFP from the Rosa ${ }^{Z s G}$ allele (Figure 2A). All LCOs exhibited steady growth in continuous culture and were passaged every 5 to 7 days.

RNA-seq was performed on LCO1 to LOC5 $(n=4,4,4$, 4 , and 3, respectively). As expected, a consistent, high level of up-regulation of liver stem cell markers in all organoids, compared with that of PPTR primary tumors, was found (Figure 2B, Supplemental Figure S1). Conversely, liver differentiation markers such as albumin and alcohol dehydrogenase were significantly down-regulated in all the LCOs, similar with that of HG-PPTR tumors (Figure 2B). Therefore, the 3D liver stem cell culture was able to propagate tumor cells with strong stemness characteristics from PPTR primary tumors.

\section{LCOs from Primary Mouse HCC Generate Widespread Invasion and Metastases on Orthotopic Transplantation}

In vivo tumorigenicity of LCOs was next examined by orthotopic liver transplantation. To accurately deliver cells to the liver with minimal animal manipulation, a noninvasive, ultrasound-guided intrahepatic injection method was developed to transplant cells into the median liver lobe of CD-1 Nude mice (Figure 3A). LCO1 to LCO5 were injected individually into the liver of CD-1 NU/NU mice at $1 \times 10^{5}$ cells per animal. Among the $5 \mathrm{LCOs,} \mathrm{LCO1} \mathrm{to} \mathrm{LCO3} \mathrm{showed} \mathrm{high}$ tumorigenicity in vivo, but $\mathrm{LCO} 4$ and LCO5 failed to drive tumor formation (median survival, 58, 100, 163, 361, and 300 days, respectively) (Figure 3B, Supplemental Table S2). Fullbody necropsies of $>50$ mice injected with $\mathrm{LCO} 1, \mathrm{LCO} 2$, or $\mathrm{LCO} 3$ revealed consistent formation of $\mathrm{GFP}^{+}$tumors in the liver (Figure 3, C-E), as well as extensive lymphatic invasion and intrahepatic, abdominal, and pulmonary metastases (Figure 3F). The tumor burden in each organ was categorized as level 1,2, or 3 according to the percentage of the tissue area occupied by $\mathrm{GFP}^{+}$tumors. Level 1 indicated the lowest tumor

Table 1 GSEA Shows the Enrichment of Gene Sets Related to Human Poor Prognosis HCC in High-Grade PPTR Tumors Compared with PPTR Primary Tumors

\begin{tabular}{lll}
\hline Gene set name & NES & Nominal $P$ value \\
\hline YOSHIOKA_LIVER_CANCER_EARLY_RECURRENCE_UP & 1.565 & 0.002 \\
WOO_LIVER_CANCER_CC_SIGNATURE_POOR_PROGNOSIS_UP & 1.442 & 0.002 \\
LIAO_METASTASIS & 1.424 & 0.000 \\
LEE_LIVER_CANCER_SURVIVAL_DN & 1.400 & 0.038 \\
WO0_LIVER_CANCER_RECURRENCE_UP & 1.354 & 0.033 \\
LEE_LIVER_CANCER_SURVIVAL_UP & -1.515 & 0.014 \\
WO0_LIVER_CANCER_CC_SIGNATURE_POOR_PROGNOSIS_DN & -1.482 & 0.069 \\
\hline
\end{tabular}

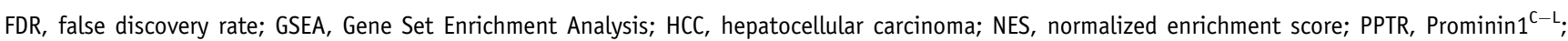
$\operatorname{Pten}^{f(x / f l x} ; \operatorname{Tp} 53^{f(x) f l x} ; \operatorname{Rosa}^{Z s G}$. 
A
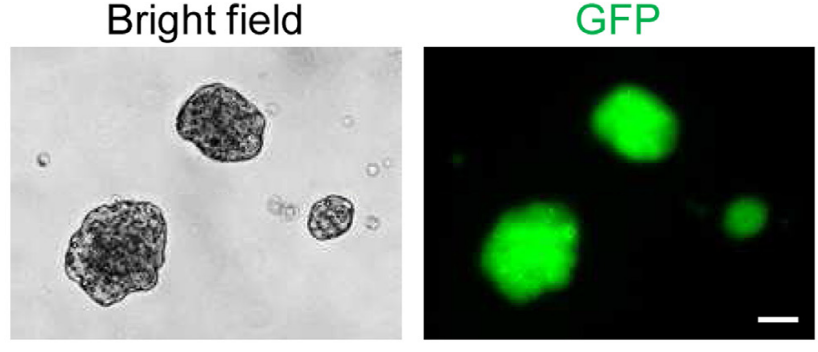

B
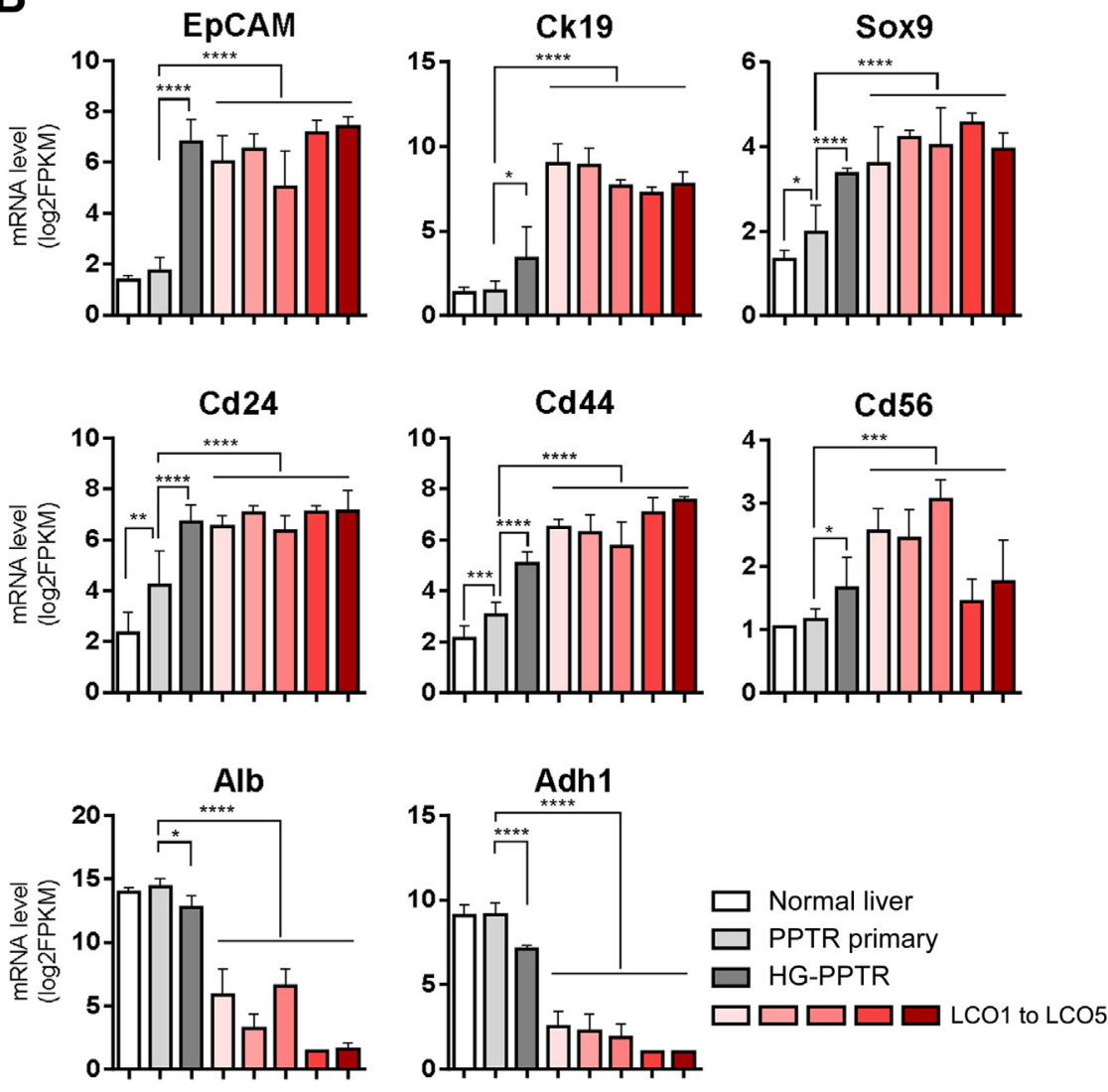

Figure 2 Three-dimensional (3D) stem cell culture produces liver organoids with stemness characteristics from Prominin $1^{\mathrm{C}-\mathrm{L}} ; \operatorname{Pten}^{f l x / f l x}$; $T p 53^{f(x) f l x} ; R_{0 s a^{2 s G}}$ (PPTR) primary liver tumors. A: Representative images of green fluorescent protein $(\mathrm{GFP})^{+}$liver cancer organoids (LCOs) generated from PPTR primary tumors with liver stem cell culture conditions. B: RNA expression levels of the indicated liver stem cell and differentiation markers in healthy liver, PPTR primary tumors, high-grade (HG)-PPTR tumors, and LCOs. ${ }^{*} P<0.05,{ }^{* *} P<0.01,{ }^{* *} P<0.001$, and $* * * * P<0.0001$ each group versus PPTR primary tumors (unpaired $t$-tests). Scale bar $=50 \mu \mathrm{m}$. Adh1, alcohol dehydrogenase; Alb, albumin; EpCAM, epithelial cell adhesion molecule; FPKM, fragments per kilobase of transcript per million mapped reads; Sox9, SRY-related HMG-box 9. burden, whereas level 3 was indicative of the highest tumor burden. Overall, LCO1 and LCO2 demonstrated similarly high metastatic potential, and LCO3 generated relatively fewer and smaller tumors, although the tumor burden varied between individual mice within each LCO line (Figure 3G). Nevertheless, it was apparent that a subset of LCOs generated from localized PPTR primary tumors was capable of driving advanced liver tumorigenesis in vivo.

\section{LCO-Driven Tumors Molecularly Recapitulate the Spontaneous Metastases of PPTR Mice}

Because tumor phenotypes were enhanced in the LCO transplantation model, its biological fidelity to the parental PPTR genetic model was studied. The RNA-seq gene expression profiles of LCO-driven primary $(n=8)$ and metastatic ( $n=10$, including two intrahepatic, three peritoneal, and five pulmonary metastases) tumors were compared with that of previously profiled tumor-adjacent liver tissues, primary, and matched HG tumors in PPTR mice (Supplemental Table S1). Unsupervised hierarchical clustering was performed with the top differentially expressed genes with a mean absolute deviation score $>1$. Remarkably, both LCO-driven primary and metastatic tumors were closely grouped with the five HG-PPTR tumors, and these three types of tumors formed a distinct cluster that separated from the tumor-adjacent controls and PPTR primary tumors (Figure 4A). Independent principal component analysis revealed similar molecular profiles between HG-PPTR and LCO-driven tumors, particularly with LCO primary tumors in the liver (Figure 4B). 
A
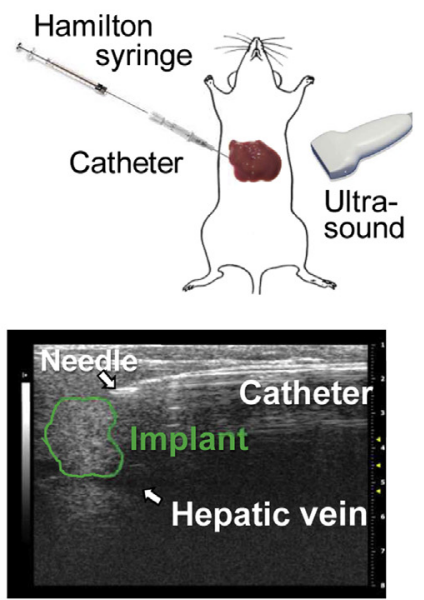

C

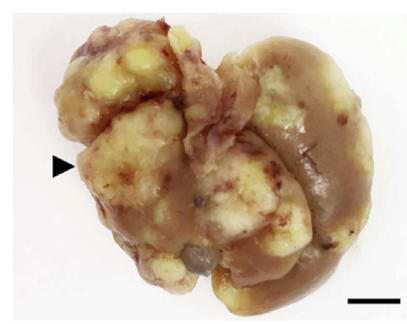

B

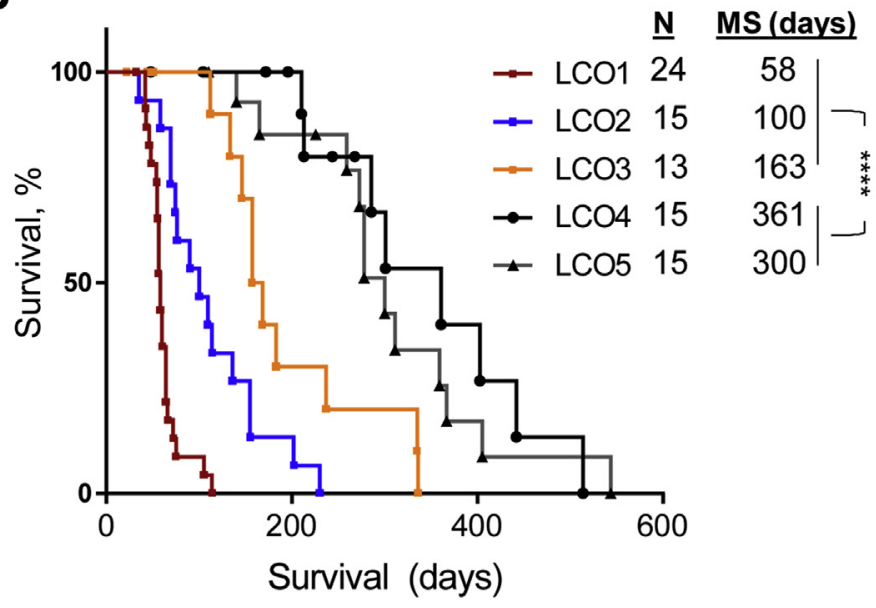

D

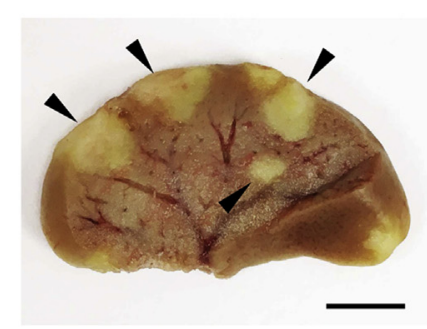

E

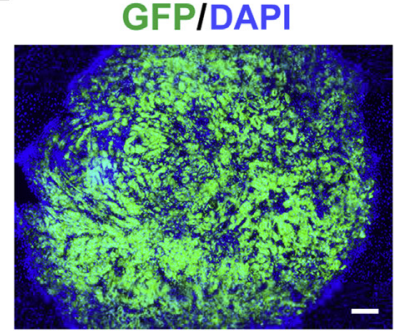

F

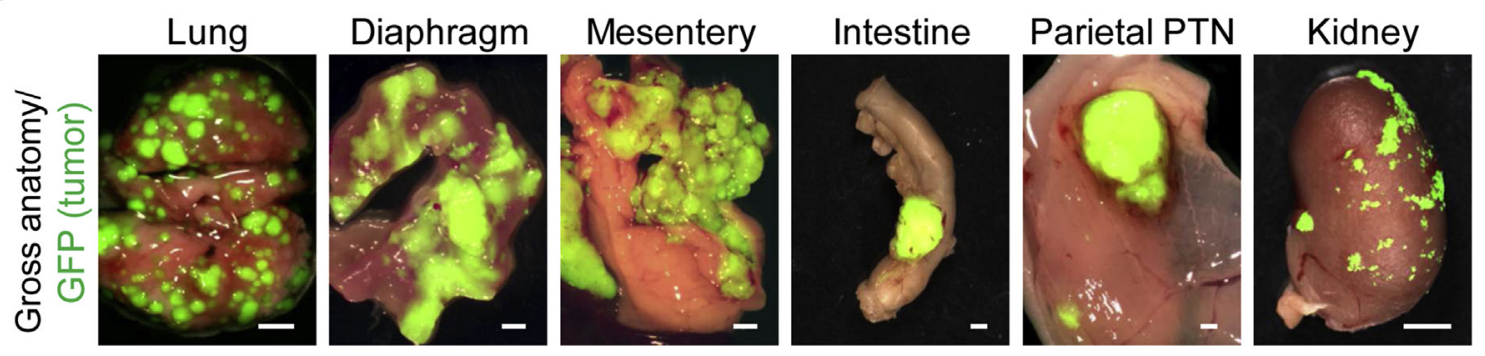

G

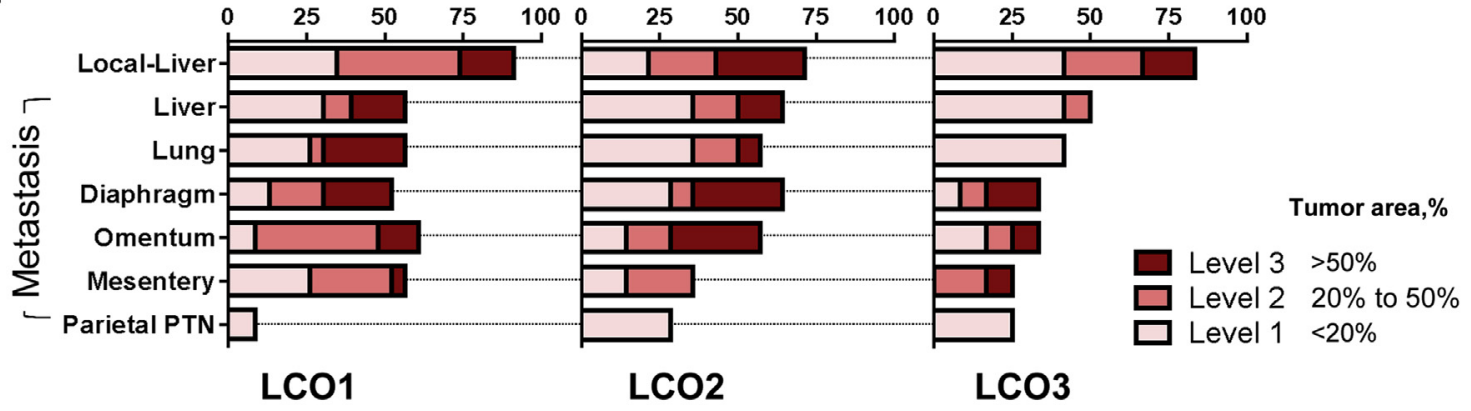

Figure 3 A subset of liver cancer organoids (LCOs) generate highly metastatic secondary tumors in vivo after orthotopic transplantation. A: Top panel shows schematic demonstration of the ultrasound-guided intrahepatic injection. Bottom panel shows representative ultrasound image of an LCO-injected liver. B: Survival curves of mice individually transplanted with LC01 to LC05. C: A representative gross image of liver tumors in LC0 recipient mice. Arrowhead shows the injected liver lobe. D: A cross section of the left lobe of the liver shown in C. Arrowheads show intrahepatic metastases. E: Green fluorescent protein (GFP) fluorescence microscopy of a liver tumor section. F: Representative whole-organ gross anatomy and GFP overlay of metastases in the indicated organs in LCO recipient mice. G: Quantification of metastatic tumor burden in the indicated organs in animals transplanted with LC01 to LC03. ${ }^{*} * * P<0.0001$ versus the indicated groups (log-rank test). Scale bars: $500 \mu \mathrm{m}(\mathbf{C}$ and $\mathbf{D}) ; 100 \mu \mathrm{m}(\mathbf{E}) ; 500 \mu \mathrm{m}(\mathbf{F})$. MS, median survival; N, number of recipient mice; PTN, peritoneum. 
A

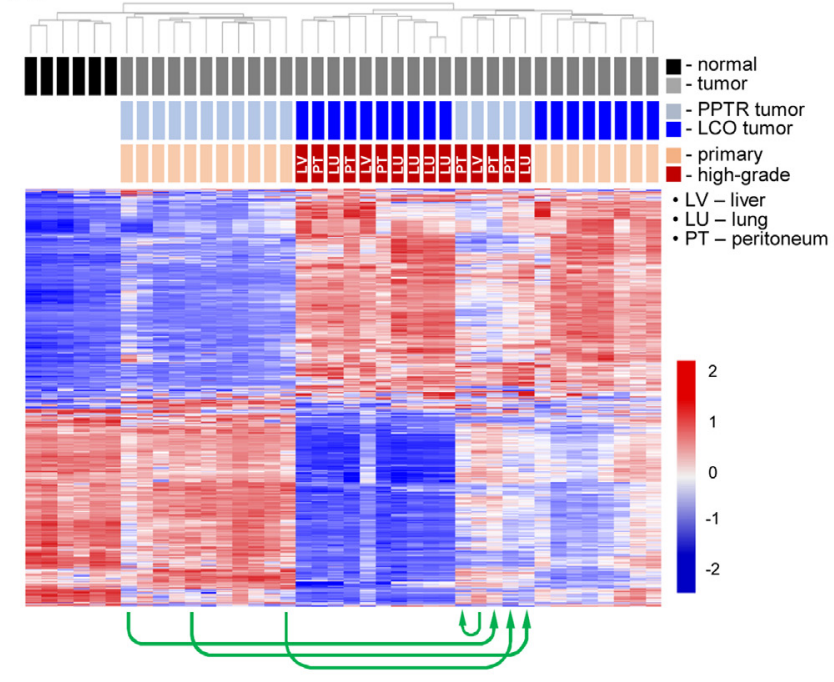

B

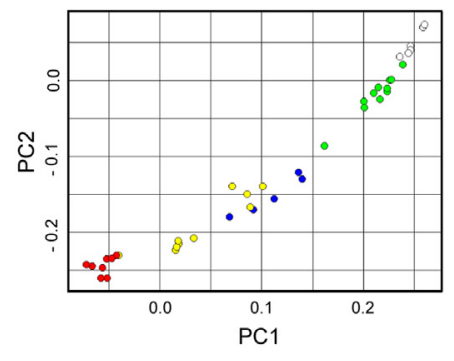

Normal liver

PPTR primary

HG-PPTR

LCO-driven primary

LCO-driven metastasis

C

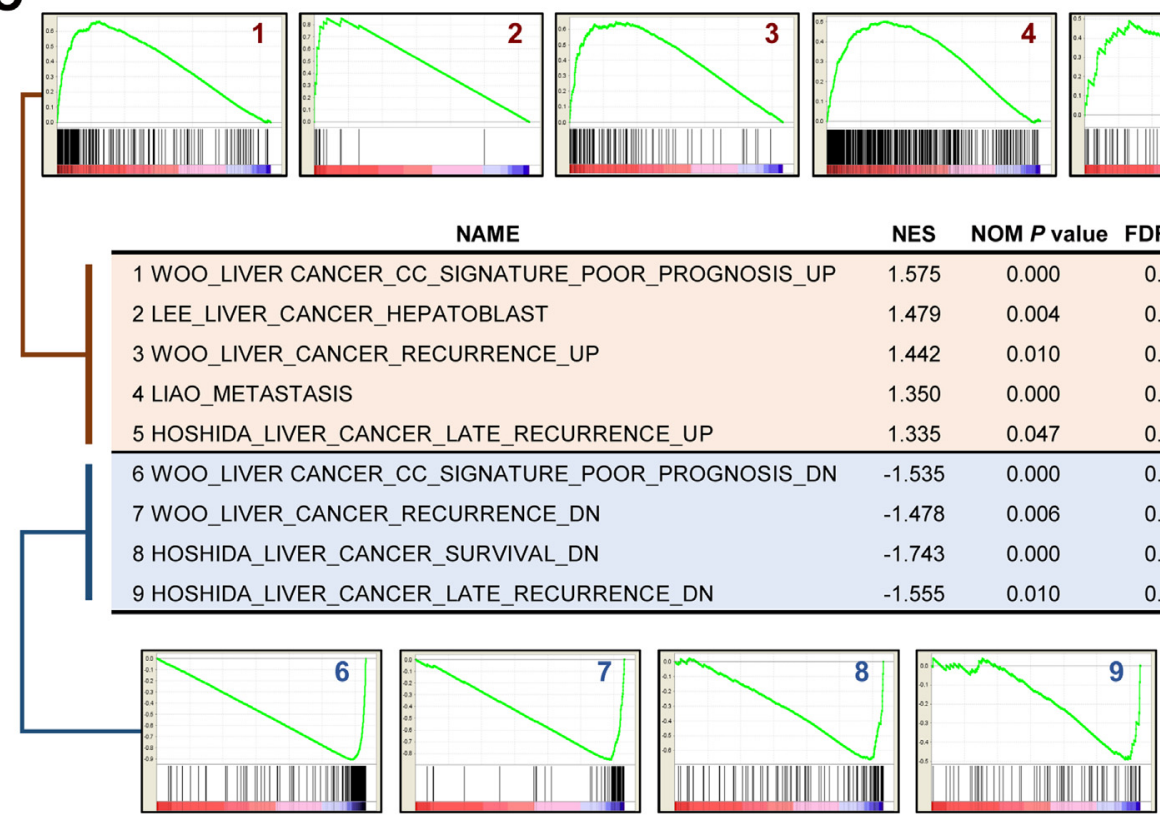

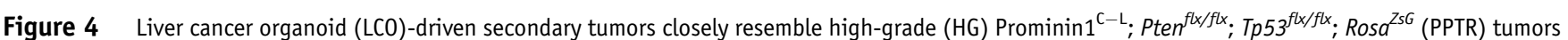
and human liver cancer. A: Unsupervised hierarchical clustering with the use of the top differentially expressed genes (mean absolute deviation $>1$ ) among the indicated liver tumor and control samples. Arrows show matched primary and HG tumors in PPTR mice. B: Principle component analysis of the groups of samples shown in A. C: Gene Set Enrichment Analysis of positively and negatively enriched gene sets of human poor prognosis hepatocellular carcinoma in LCO-driven liver tumors, compared with that of PPTR primary tumors. PC, principal component.

GSEA was performed to assess the similarity between LCO-driven tumors and high-risk human liver cancer (Figure 4C). Compared with that of their parental PPTR primary tumors, the LCO-driven tumors showed significant enrichment of a number of gene sets associated with recurrence, metastasis, and poor prognosis in human HCC, including a previously reported hepatoblast gene signature that is not enriched in HG-PPTR tumors. ${ }^{4}$ This suggested that the stemness characteristics were highly augmented in the LCO-driven tumors. To determine whether a transition to a CC-like phenotype similarly occurred in LCO-driven HCC development, the two CC-like gene sets were examined. Indeed, these two gene sets were enriched with the highest enrichment scores in LCO tumors compared with that in PPTR primary tumors (Figure 4C). Because the LCO-driven tumors had higher enrichment scores in the $\mathrm{CC}$ signatures than the HG-PPTR tumors when both were compared with the same PPTR primary tumors, a further enhanced CC gene expression signature was apparent in LCO-driven tumors. Detailed histologic characterization was next performed to determine whether a morphologic transition from HCC to CC was also apparent in LCO-driven tumors. 
A

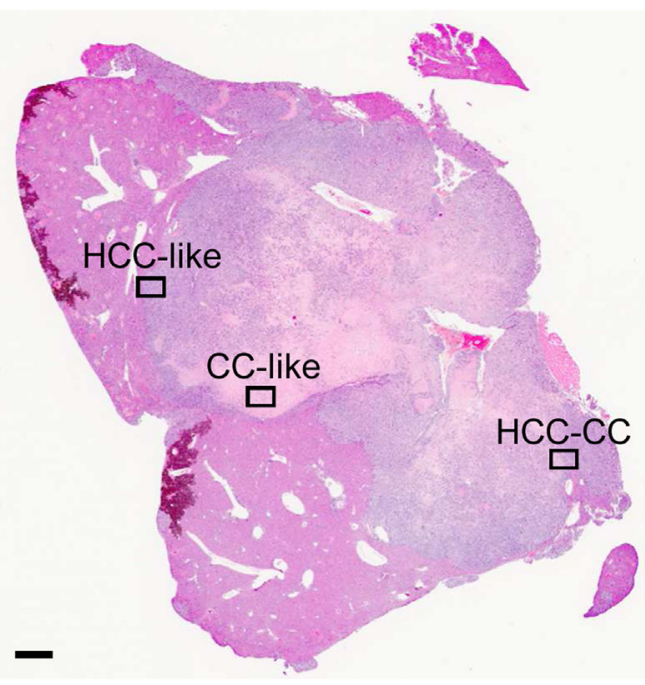

B
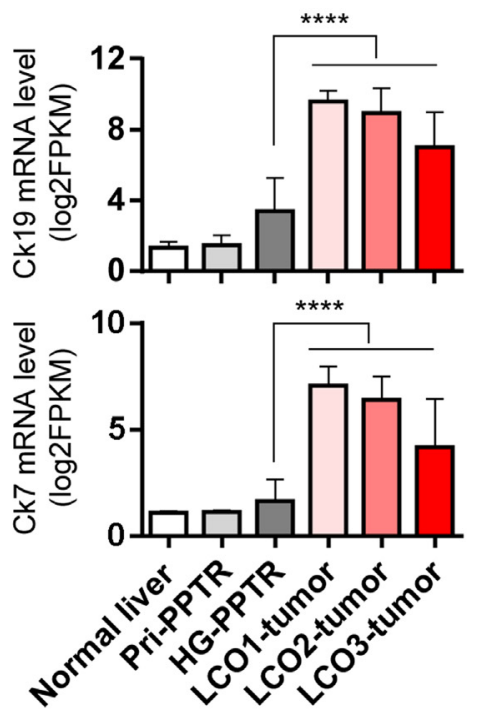

C
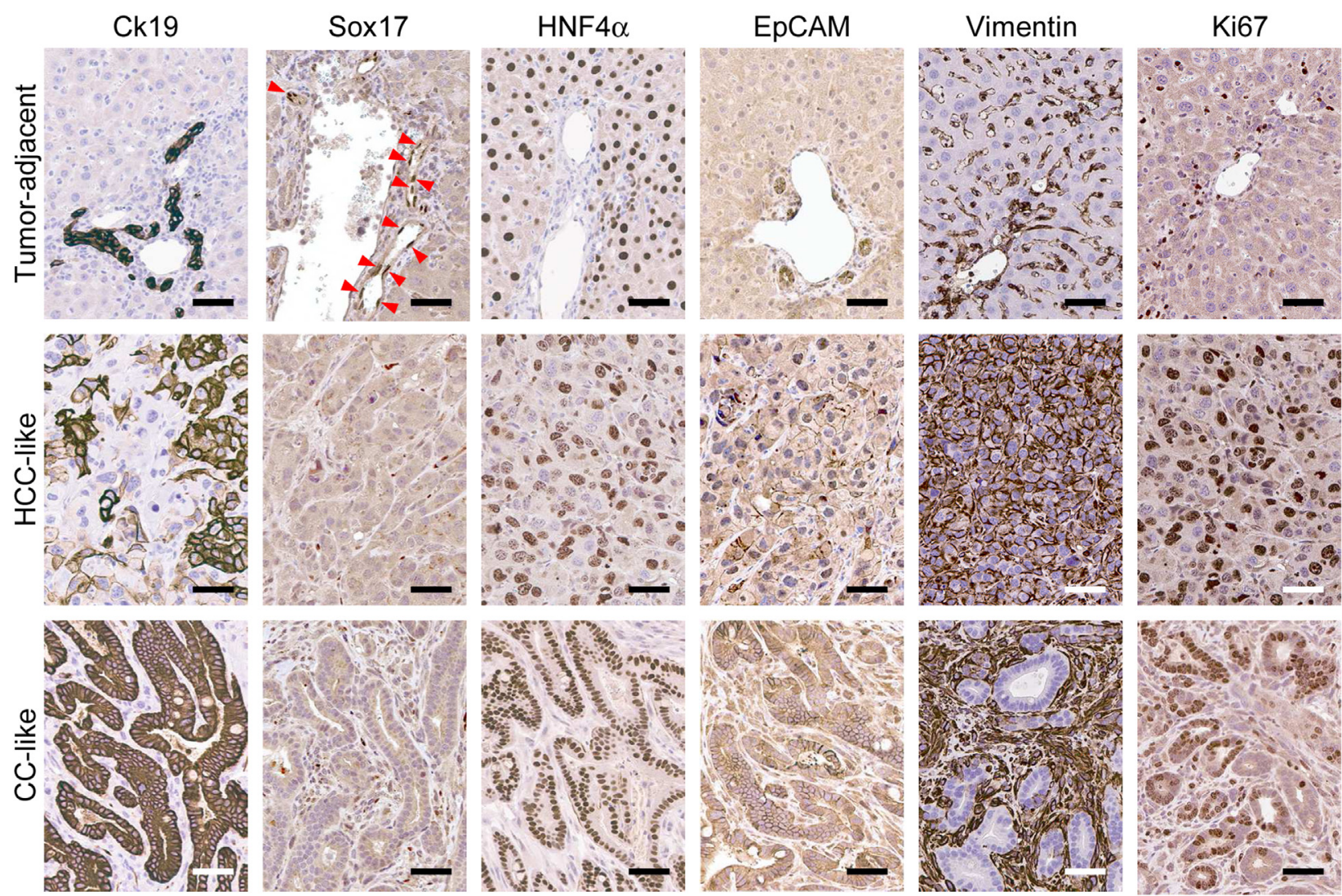

Figure 5 Liver cancer organoid (LCO)-driven tumors display combines hepatocellular carcinoma (HCC) and cholangiocarcinoma (CC) histopathology. A: Left panel shows hematoxylin and eosin staining of a representative LCO-driven tumor in the liver. Right panels show higher-magnification images of the three boxed areas in the left panel. B: RNA expression of $\mathrm{Ck} 19$ and Ck7 in the indicated tumor groups. C: Immunostaining of the indicated markers in the HCCand CC-like lesions in LCO-driven tumors in the liver. Arrowheads show SRY-related HMG-box 17 (Sox17)-positive normal cholangiocytes. ${ }^{* * * * P<0.0001 .}$ Scale bars: $1 \mathrm{~mm}$ (A, left); $50 \mu \mathrm{m}$ (A, right, and $\mathbf{C})$. EpCAM, epithelial cell adhesion molecule; FPKM, fragments per kilobase of transcript per million mapped reads; HNF $4 \alpha$, hepatocyte nuclear factor $4 \alpha$; Pri, primary. 
LCO-Driven Tumors Display Combined Hepatocellular and Cholangiocarcinoma Histopathology

Consistent with their significant enrichment of CC-like gene expression signature, most LCO-driven tumors displayed a prominent $\mathrm{CHC}$ morphology, which was not observed in their parental PPTR tumors. HCC- and CC-like lesions as well as regions with HCC-CC transition were present in LCO-driven primary and metastatic tumors (Figure 5A, Supplemental Figure S2). Consistently, cholangiocytic markers $C k 7$ and $C k 19$ were among the most up-regulated genes in LCO-driven tumors compared with that of HGPPTR tumors (Figure 5B). High levels of Ck19 protein were detected in both HCC- and CC-like regions within LCO-driven tumors by immunostaining (Figure 5C). Consistent with liver cancer in patients, Sox17, a key driver of cholangiocyte differentiation and a tumor suppressor of both HCC and CC, showed very low expression in both HCC- and CC-like lesions in LCO-driven tumors in contrast to its high nuclear levels in normal cholangiocytes (Figure 5C) ${ }^{47,48}$ Interestingly, hepatocyte nuclear factor $4 \alpha$, a hepatocyte lineage marker, showed high levels of expression in both HCC- and CC-like lesions in the LCOdriven tumors, which may suggest a similar hepatocyte origin of HCC- and CC-like cells in these tumors (Figure 5C).

Compared with PPTR tumors, both HCC- and CC-like regions in LCO-driven tumors showed similar high levels of up-regulation of markers associated with advanced liver cancer such as EpCAM, Vimentin, and Ki67, whereas no clear difference in their expression was found between these two types of lesions (Figure 5C, Supplemental Figure S3). No further increase in the expression of these markers was found in LCO-driven distant metastases compared with those in the liver (Supplemental Figure S3). To determine the association of stemness with this increased aggressive of LCO-driven tumors, the expression of those liver stem cell markers that showed higher levels in HG tumors than primary tumors in PPTR mice was examined. Cd56 and $\mathrm{Cd} 24$ showed higher expression in LCO-driven tumors than in HG-PPTR tumors. However, no difference in the expression of Cd44 and Sox9 was found between HG-PPTR and LCO-driven tumors, and $\alpha$-fetoprotein and intercellular adhesion molecule 1 showed reduced expression in LCOdriven tumors (Supplemental Figure S4). Therefore, expression of these common liver stem cell markers showed various levels of association with liver cancer progression in this model. To identify signaling pathways driving the advanced tumor progression in the LCO transplantation model, KEGG pathway enrichment analysis was performed, and it revealed significantly increased activities of $\mathrm{Wnt} / \beta$ catenin, Hippo, phosphatidylinositol 3-kinase/Akt/mechanistic target of rapamycin, and transforming growth factor- $\beta$ signaling pathways in LCO-driven tumors compared with PPTR primary tumors, consistent with the key roles of these major signaling pathways in driving advanced $\mathrm{HCC}$ development (Supplemental Table S3). ${ }^{49-53}$ Among them, Wnt//-catenin signaling showed highest levels of activation (Supplemental Figure S5). Most components of the Notch signaling pathway, another major signaling pathway previously implicated in both HCC and CC development, ${ }^{52,54}$ also showed a marked increase in their expression in LCO-driven tumors compared with PPTR tumors (Supplemental Figure S6).

\section{D Stem Cell Culture Does Not Induce Cholangiocyte Differentiation in LCOs Generated from Mouse Primary HB}

To examine whether the acquisition of a CC phenotype in LCO tumors occurred from an artificial induction of cholangiocyte differentiation by in vitro stem cell culture, stem cell cultures and orthotopic transplantations were performed with a hepatoblastoma (HB) model generated by targeting Prom1 $^{+}$neonatal liver progenitors with an activating Notch1 mutation (PNR mice). ${ }^{12}$ Similar with that of PPTR mice, PNR mice developed frequent primary tumors in the liver but rare metastases (metastasis rate $=1.9 \%, n=2$ of 108). Primary tumors in PNR mice histologically resembled fetal subtype $\mathrm{HB}$, and their RNA-seq gene expression profiles $(n=9)$ were enriched with a reported human HB gene set when compared with healthy livers by GESA (Figure 6A). Cells isolated from six PNR primary tumors were cultured in the same liver stem cell cultures, and 3D organoids were formed within 3 days, which were named HB organoid 1 to 6 (HBO1 to HBO6) to distinguish them from LCOs grown from PPTR tumors. HBO1 to HBO6 exhibited significantly increased expression levels of multiple liver stem cell markers than their PNR-HB primary tumors (Figure 6B). HBO1 to HBO6 were orthotopically transplanted in the livers of CD-1 NU/NU mice $\left(1 \times 10^{5}\right.$ cells/mouse). $\mathrm{HBO} 1$ and $\mathrm{HBO} 2$ produced metastatic tumors (metastasis rate $=42.1 \%$ and $28.6 \%$ for $\mathrm{HBO} 1$ and $\mathrm{HBO} 2$, respectively), and $\mathrm{HBO} 3$ to $\mathrm{HBO} 6$ were not tumorigenic in vivo (median survival $=149,225,347,380,396$, and 364 days, respectively) (Figure 6C, Supplemental Table S2). HBO-driven metastases were predominantly found in the liver, peritoneum, and lung (Figure 6D, Supplemental Table S2). Consistent with this increase in tumor metastasis, tumor histologic characteristics shifted from the fetal subtype of parental PNR-HB tumors to a more aggressive embryonal subtype in HBO-driven tumors. Such features included high nuclear-to-cytoplasmic ratios, poorly defined cell borders, and increased mitotic activity (Figure 6E).

The gene expression of HBO-driven tumors was profiled by RNA-seq $(n=7)$ (Supplemental Table S1). GSEA found no enrichment of any gene sets associated with poor prognosis in human HCC when the gene expression profiles of HBO-driven tumors were compared with those of their parental PNR-HB tumors (Supplemental Table S4). Therefore, HBO-driven tumors were molecularly distinct from HCC tumors. Importantly, no acquisition of histologic or 
A

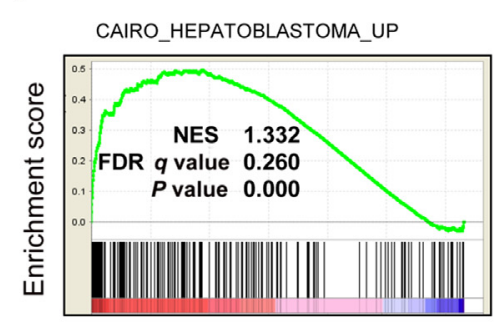

C

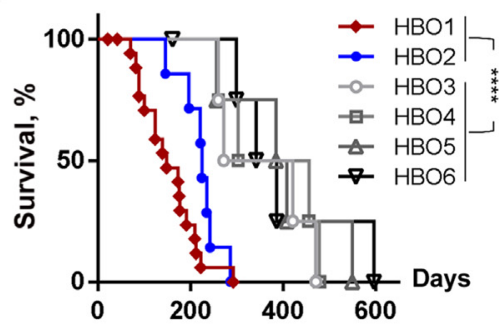

$\mathbf{E}$

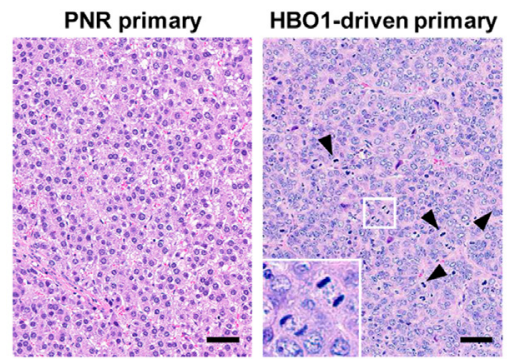

B

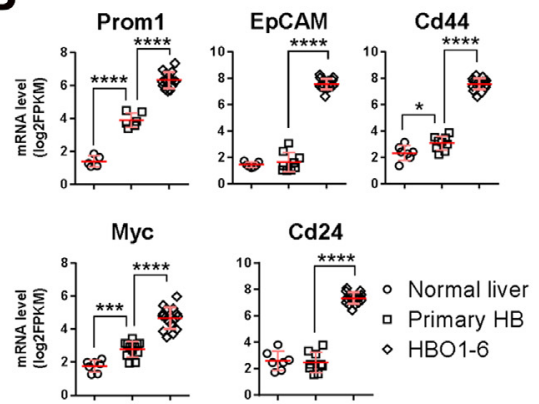

D
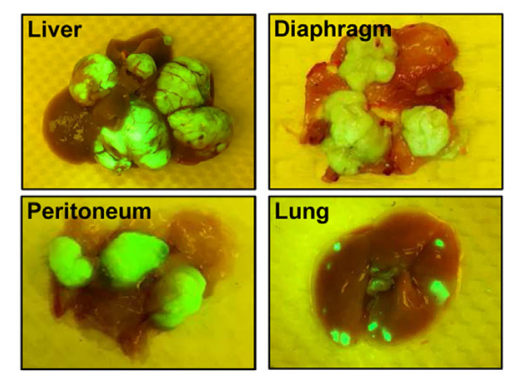

$\mathbf{F}$

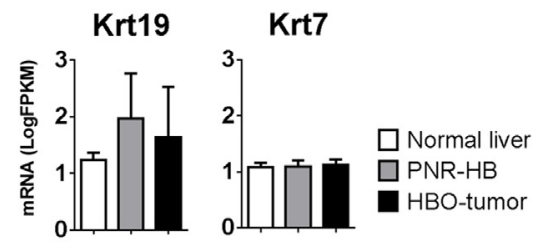

Figure 6 Tumor organoids generated from primary mouse hepatoblastoma (HB) similarly drive high-grade tumors on serial orthotopic transplantation which do not acquire cholangiocarcinoma (CC)-like traits. A: Gene Set Enrichment Analysis enrichment plot of a human $\mathrm{HB}$ gene set in Prominin $1^{\mathrm{C}-\mathrm{L}}$; Rosa ${ }^{\mathrm{NICD} 1 /+} ; \operatorname{Rosa}^{Z S G}$ (PNR)-HB tumors compared with that of healthy liver. B: RNA expression levels of the indicated liver stem cell markers in healthy liver, PNR primary HB, and HB organoids (HBOs). C: Survival curves of mice transplanted with the indicated HBOs. D: Representative whole-organ images overlaid with green fluorescent protein (GFP) of the metastases in the indicated organs in HB01transplanted mice. E: Hematoxylin and eosin staining of representative PNR primary and HB01driven tumors in the liver. Arrowheads in the right panel show mitotic figures. Inset shows highermagnification image of the boxed area showing two cells with mitotic figures. F: RNA expression of Ck19 and Ck7 in healthy liver, PNR primary tumors, and $\mathrm{HBO}$-driven tumors. ${ }^{*} P<0.05,{ }^{* * *} P<0.001$, and $* * * * P<0.0001$ all samples versus PNR primary HB (unpaired $t$-tests) $(\mathbf{B}) ; * * * * P<0.0001$ versus the indicated groups (log-rant test) (C). Scale bars: $50 \mu \mathrm{m}$ (E). EpCAM, epithelial cell adhesion molecule; FDR, false discovery rate; FPKM, fragments per kilobase of transcript per million mapped reads; NES, normalized enrichment score; Prom1, prominin-1. molecular CC-related features in HBO-driven tumors was found. The CC gene signatures were not enriched, and the cholangiocytic $\mathrm{Ck} 19$ or $\mathrm{Ck} 7$ markers were not up-regulated in HBO-driven tumors, compared with that of their parental PNR primary tumors (Figure 6F). These findings indicated that the transition to a CC-like phenotype observed in the PPTR LCO-driven tumors was not induced by stem cell culture conditions but rather was associated with advanced HCC progression in the PPTR mouse model.

\section{Extracellular Vesicle Proteins Are Increased in the Plasma of Mice Bearing LCO-Driven HG Tumors}

Because it was apparent that the $\mathrm{HG}$ tumors driven by organoids derived from the PPTR and PNR models have little overlap in their similarity to hepatic progenitors or CC-like tumors, an unbiased analysis was next performed to identify any potential molecular or cellular features shared by the advanced tumors in both models. Of interest, gene ontology enrichment analysis revealed a universal enrichment of EV components in LCO- and HBO-driven metastatic tumors compared with the localized primary tumors in the genetic models (Figure 7A). Interestingly, metastatic LCOs (ie, LCO1, LCO2, and LCO3) and HBOs (ie, $\mathrm{HBO} 1$ and $\mathrm{HBO} 2$ ) also showed similar enrichment of EV secretion processes compared with that of their counterparts which failed to drive tumorigenesis in vivo (Figure 7A). Large numbers of $\mathrm{GFP}^{+} \mathrm{EV}$ particles were consistently found in the tissues within and adjacent to the sites of LCO-driven metastases at various anatomic locations and in the plasma (Figure 7B). Mass spectrometry was used to determine whether a tumor-specific protein profile may define EVs in the blood of mice bearing metastatic tumors. EVs from mice with LCO-driven metastatic tumors displayed a distinct protein profile, compared with those of nontransplanted control mice. Among the top 50 most abundant proteins packed in the EVs of mice with metastatic tumors, multiple proteins known to drive metastasis of various cancer types, such as secreted phosphoprotein $1,{ }^{55}$ mucin $13,{ }^{56}$ epidermal growth factor receptor kinase substrate $8,{ }^{57} \mathrm{C}-\mathrm{X}-\mathrm{C}$ motif chemokine receptor $2,{ }^{58}$ and brain-specific angiogenesis inhibitor 1-associated 
A

LCO-tumors versus PPTR-tumors

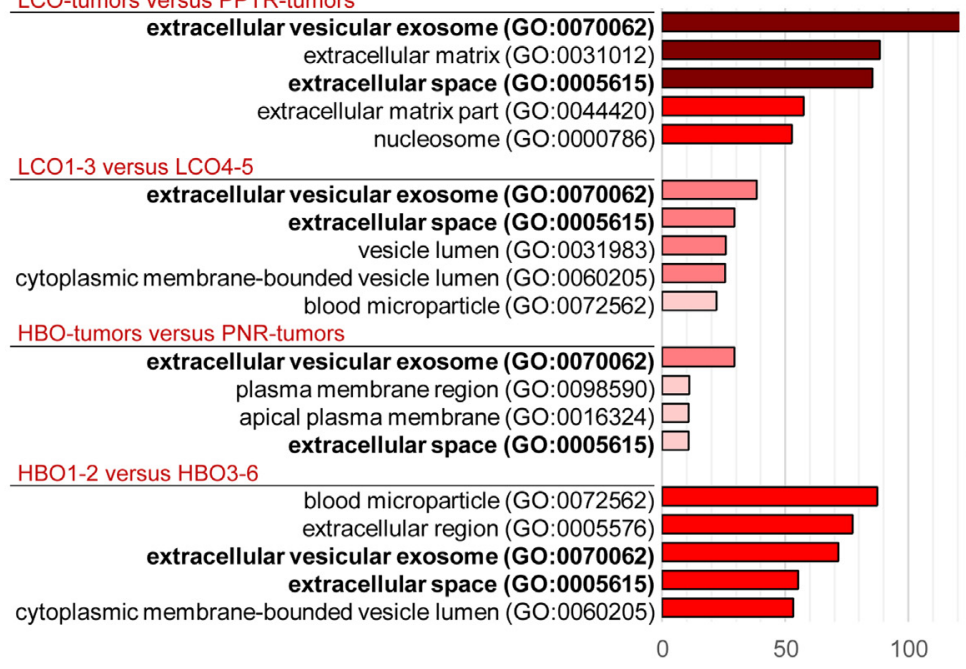

B
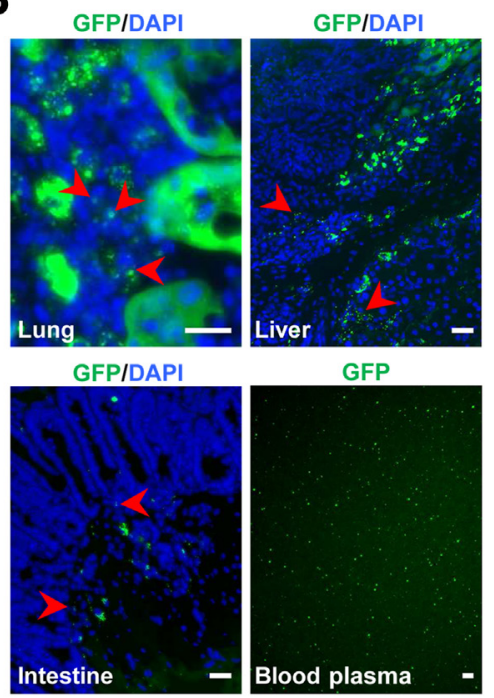

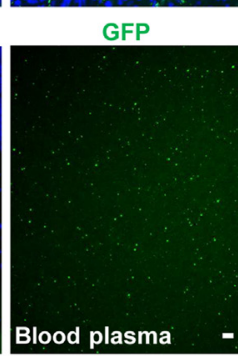

\section{C}

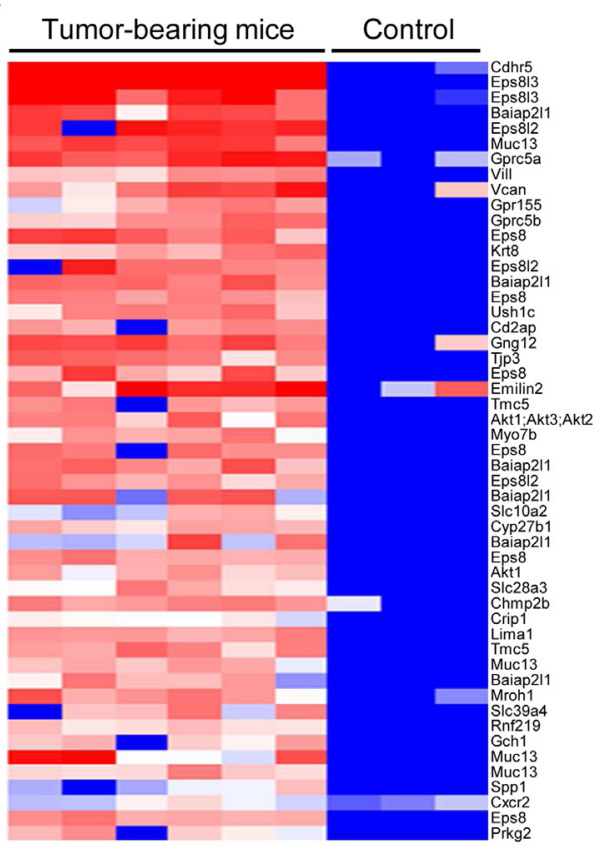

Figure 7 Enrichment of extracellular vesicle (EV) components in metastatic Prominin $1^{\mathrm{C}-\mathrm{L}} ; \operatorname{Pten}^{f(x) f f(x} ; \operatorname{Tp} 53^{f(x / f(x)} ; \operatorname{Ros} a^{2 s G}$-liver cancer organoids (PPTR-LCOs), Prominin $1^{\mathrm{C}-\mathrm{L}}$; Rosa $\mathrm{RICD} 1 /+^{\mathrm{N}}$; Rosa ${ }^{2 S G}$-hepatoblastoma organoids (PNR-HBOs), and the tumors they generated compared with that of their nonmetastatic counterparts. A: Graph of gene ontology (G0) enrichment analysis of the cellular components in the listed groups. Bolded lines indicate EV-related cellular components. B: Green fluorescent protein (GFP) fluorescence image showing the EVs in the indicated tumor regions and plasma of mice transplanted with metastatic LCOs. Arrowheads show GFPpositive EVs. C: Top 50 most abundant proteins identified by mass spectrometry in the plasma of mice transplanted with metastatic LCOs and control animals. Scale bar $=50$ $\mu \mathrm{m}$.

protein 2-like protein 1 (Baiap211), ${ }^{59}$ were identified (Figure 7C, Supplemental Table S5). Among these proteins, only secreted phosphoprotein 1 has been previously established as a serum biomarker for HCC detection. ${ }^{60}$ Therefore, this result indicated that changes in EV protein content were one of the main biological features associated with the development of $\mathrm{HG}$ liver tumors, and profiling plasma $\mathrm{EV}$ proteins in patients can potentially be a promising approach to develop novel liver cancer detection biomarkers.

\section{Discussion}

We previously reported that deletion of Pten and Tp53 in bipotential Prom $1^{+}$liver progenitors induces formation of frequent primary HCC tumor and rare invasive and metastatic tumors. ${ }^{12}$ Targeting Prom $1^{+}$progenitors did not generate primary tumors with mixed HCC and CC features despite the ability of these cells to produce both lineages during normal liver development. However, the rare $\mathrm{HG}$ tumors developed in this model showed substantial increase in CC-related molecular features compared with primary tumors while retaining a HCC morphology. From these observations, it was hypothesized that CC-like traits can be an acquired feature of HCC tumors during their advanced development. A novel primary tumor organoid-based transplantation mouse model was subsequently developed to test this hypothesis. With the use of a 3D stem cell culture system, it was shown that cells from nonmetastatic primary 
PPTR tumors can readily generate LCOs with stemness properties that, when injected orthotopically into the mouse liver, generate a reproducible model of aggressive liver cancer with widespread invasion and metastasis. LCOdriven tumors exhibited striking molecular similarities with that of HG human HCC and the invasive/metastatic tumors in the parental PPTR genetic model. More importantly, these tumors showed a predominant CHC morphology and high levels of enrichment of CC-like gene expression signatures. These results suggest that tumors with mixed HCC and CC features found in humans, or at least a subset of these tumors, represent a more advanced developmental stage of HCC driven by highly plastic tumor cells with stemness properties, which is consistent with the more aggressive behaviors of such tumors than classic HCC in patients.

Phenotypic plasticity of liver cancer at advanced stages has long been speculated from the wide and continuous spectrum of liver cancer pathology found in patients. Previous studies on rat and mouse modeling of liver cancer have shown that CC tumorigenesis can initiate from mature hepatocytes and acquisition of cholangiocytic marker Ck19 can occur during HCC progression. ${ }^{54,61-65}$ However, coexistence of HCC and CC morphology that is found in a small subset of human patients has not been previously modeled in experimental animals. Although studies that focus on such CHC tumors with the use of patient samples have revealed HPC features and supported a cell of origin of HPC, none of them ruled out the possibility that de- or transdifferentiation of HCC cells may account for the formation of the CC morphology seen in these tumors because of the lack of tracking morphologic and pathologic evolution of individual patient tumors in these studies. ${ }^{8}$ In this study, we were able to efficiently model progression of aggressive HCC in mice and revealed that CC-like characteristics can be acquired during $\mathrm{HCC}$ progression to $\mathrm{HG}$ invasive and metastatic tumors, providing the first evidence to support that $\mathrm{CHC}$ tumors found in human patients may represent a more advanced developmental stage of HCC.

A number of major signaling pathways showed significantly elevated activities during LCO-driven tumorigenesis, including Wnt/ß-catenin, Hippo, phosphatidylinositol 3-kinase/Akt/mechanistic target of rapamycin, transforming growth factor- $\beta$, and Notch signaling pathways. Because they have all been implicated in both HCC and $\mathrm{CC}$ development in human patients, it is not clear whether some of the pathways may play a specific role in promoting the development of CC-like lesions in LCOdriven tumors. ${ }^{49-53,66-68}$ Future studies to compare tumor samples isolated from HCC- and CC-like areas will likely provide valuable insight into the differential molecular evolution of these morphologically distinct lesions within the same tumor.

Organoid cultures were repeated with primary tumors from a $\mathrm{HB}$ genetic mouse model and it was found that HBO-driven tumors did not develop CC-like features when they similarly displayed much more aggressive phenotypes than the parental genetic model. This result indicates that the 3D stem cell culture conditions do not artificially induce cholangiocytic differentiation. Therefore, the acquisition of CC-like traits of LCO-driven tumors is not a universal feature of advanced development of different liver cancer subtypes. Because it is well known that genetic mutations dictate histologic subtypes of liver cancer, it is likely that the genetic drivers of an individual tumor contribute to its ability to acquire CC-like traits during progression. ${ }^{69,70}$ It will be informative to repeat this study with other liver cancer mouse models as well as patient tumors that harbor different genetic mutations to determine the role of specific genetic factors on liver cancer plasticity.

Tumor organoids derived from distinct $\mathrm{HCC}$ and $\mathrm{HB}$ primary tumors were found not to be equally tumorigenic despite sharing similarly high levels of many liver stem cell markers. In addition, expression of a group of common liver stem cell markers showed variable levels of or no association with tumor aggressiveness in our models. These results suggest that expression of liver stem cell markers may not be an independent prognostic parameter for liver cancer despite the general association between stemness and HCC aggressiveness. $^{15,19}$ In searching for common features consistently associated with advanced tumor phenotypes in both HCC and HB models presented in this study, a remarkable enrichment of $\mathrm{EV}$ components was found in the metastatic LCOs and HBOs and in the tumors they generated, compared with that of their nonmetastatic counterparts. It has been well recognized that communication between tumor cells and their microenvironment by EVs and other mechanisms is one of the key regulators of metastasis. ${ }^{71} \mathrm{EV}$ particles, particularly tumor-specific exosomes, have been widely demonstrated to play a critical role in preparing a premetastatic niche for tumor cell dissemination and are a promising diagnostic tool for cancer detection. $^{72-74}$ Indeed, the mass spectrometry findings revealed a distinct proteomic profile of EVs collected from the plasma of PPTR LCO-recipient mice, compared with that of control animals, suggesting that profiling patient plasma EV proteins can be potentially a promising novel approach for liver cancer detection and prognosis prediction. Indeed, two recently published studies that focused on serum EVs from HCC and CC patients have revealed a number of EV proteins that showed close correlations with tumor presence. ${ }^{75,76}$ Interestingly, the top EV protein found commonly up-regulated in human CC patients and CC cells, BAIAP2, is also one of the most abundant plasma EV proteins identified in our study, supporting these mice as a used model for the discovery of novel biomarkers for liver cancer detection. BAIAP2 has also been reported to promote cell proliferation in human HCC. $^{77}$ Further time-course study with the use of this highly efficient LCO-driven liver cancer mouse model will allow a detailed tracking of changes in EV protein contents, particularly at the early asymptomatic stage, which will be instrumental for the 
identification of early detection biomarkers for liver cancer with high aggressiveness potential.

Recurrent and metastatic liver cancers are highly therapy resistant. ${ }^{78,79}$ Indeed, most novel therapy trials for liver cancer fail to meet study end points. ${ }^{80}$ From recent efforts with the use of cell-based, high-throughput drug screening, many studies have shown that 3D cancer organoids are a better model system than conventional 2D cell cultures to recapitulate key tumor characteristics. ${ }^{81-83}$ The finding that LCOs grown from primary tumors can generate tumors with a transcriptional profile similar to that of $\mathrm{HG}$ tumors supports the concept that LCOs derived from patient primary tumors may be used to screen novel therapeutics for advanced forms of liver cancer, particularly when metastatic and recurrent tumor biopsies are unavailable.

\section{Conclusions}

This manuscript demonstrates the enhanced tumor heterogeneity during advanced HCC development in mice, particularly its ability to acquire CC-like traits. Modeling advanced liver cancer development in mice is an efficient approach to improve the understanding of the heterogeneity and plasticity that occurs in this often lethal cancer, which will undoubtedly facilitate the development of novel early detection biomarkers and personalized therapies for liver cancer patients.

\section{Acknowledgments}

We thank the staff of the Hartwell Center for Bioinformatics and Biotechnology, the Cell and Tissue Imaging Shared Resource, the Small Animal Imaging Core, and the Animal Resource Center at St. Jude Children's Research Hospital for providing technical assistance. We thank Nisha Badders at St. Jude Children's Research Hospital for editing the manuscript for nonintellectual content.

L.L. conducted most of the biological experiments; M.Q. performed most of the bioinformatic analyses; I.-H.C. and W.A.T. performed the mass spectrometry experiments; D.F. and J.J.Y. performed bioinformatic analyses; A.O.-T. performed statistical analyses; M.J. and C.C. conducted experiments; A.B. and D.H.L.-T. provided pathology review; L.Z. conceived and oversaw the research; and all authors wrote the manuscript.

\section{Supplemental Data}

Supplementary data related to this article can be found at https://doi.org/10.1016/j.ajpath.2017.11.013.

\section{References}

1. Torre LA, Bray F, Siegel RL, Ferlay J, Lortet-Tieulent J, Jemal A: Global cancer statistics, 2012. CA Cancer J Clin 2015, 65:87-108
2. Schmelzer E, Zhang L, Bruce A, Wauthier E, Ludlow J, Yao HL, Moss N, Melhem A, McClelland R, Turner W, Kulik M, Sherwood S, Tallheden T, Cheng N, Furth ME, Reid LM: Human hepatic stem cells from fetal and postnatal donors. J Exp Med 2007, 204: 1973-1987

3. Bosch FX, Ribes J, Diaz M, Cleries R: Primary liver cancer: worldwide incidence and trends. Gastroenterology 2004, 127: S5-S16

4. Lee JS, Heo J, Libbrecht L, Chu IS, Kaposi-Novak P, Calvisi DF, Mikaelyan A, Roberts LR, Demetris AJ, Sun Z, Nevens F, Roskams T, Thorgeirsson SS: A novel prognostic subtype of human hepatocellular carcinoma derived from hepatic progenitor cells. Nat Med 2006, 12:410-416

5. Woo HG, Lee JH, Yoon JH, Kim CY, Lee HS, Jang JJ, Yi NJ, Suh KS, Lee KU, Park ES, Thorgeirsson SS, Kim YJ: Identification of a cholangiocarcinoma-like gene expression trait in hepatocellular carcinoma. Cancer Res 2010, 70:3034-3041

6. Cazals-Hatem D, Rebouissou S, Bioulac-Sage P, Bluteau O, Blanche H, Franco D, Monges G, Belghiti J, Sa Cunha A, LaurentPuig P, Degott C, Zucman-Rossi J: Clinical and molecular analysis of combined hepatocellular-cholangiocarcinomas. J Hepatol 2004, 41: 292-298

7. Banales JM, Cardinale V, Carpino G, Marzioni M, Andersen JB, Invernizzi P, Lind GE, Folseraas T, Forbes SJ, Fouassier L, Geier A, Calvisi DF, Mertens JC, Trauner M, Benedetti A, Maroni L, Vaquero J, Macias RI, Raggi C, Perugorria MJ, Gaudio E, Boberg KM, Marin JJ, Alvaro D: Expert consensus document: cholangiocarcinoma: current knowledge and future perspectives consensus statement from the European Network for the Study of Cholangiocarcinoma (ENS-CCA). Nat Rev Gastroenterol Hepatol 2016, 13:261-280

8. Libbrecht L: Hepatic progenitor cells in human liver tumor development. World J Gastroenterol 2006, 12:6261-6265

9. Zhang F, Chen XP, Zhang W, Dong HH, Xiang S, Zhang WG, Zhang BX: Combined hepatocellular cholangiocarcinoma originating from hepatic progenitor cells: immunohistochemical and doublefluorescence immunostaining evidence. Histopathology 2008, 52: 224-232

10. Altekruse SF, McGlynn KA, Reichman ME: Hepatocellular carcinoma incidence, mortality, and survival trends in the United States from 1975 to 2005. J Clin Oncol 2009, 27:1485-1491

11. Bock BC, Stein U, Schmitt CA, Augustin HG: Mouse models of human cancer. Cancer Res 2014, 74:4671-4675

12. Zhu L, Finkelstein D, Gao C, Shi L, Wang Y, Lopez-Terrada D, Wang K, Utley S, Pounds S, Neale G, Ellison D, Onar-Thomas A, Gilbertson RJ: Multi-organ mapping of cancer risk. Cell 2016, 166: 1132-1146.e7

13. Yamashita T, Wang XW: Cancer stem cells in the development of liver cancer. J Clin Invest 2013, 123:1911-1918

14. Clevers H: The cancer stem cell: premises, promises and challenges. Nat Med 2011, 17:313-319

15. Magee JA, Piskounova E, Morrison SJ: Cancer stem cells: impact, heterogeneity, and uncertainty. Cancer Cell 2012, 21:283-296

16. Reya T, Morrison SJ, Clarke MF, Weissman IL: Stem cells, cancer, and cancer stem cells. Nature 2001, 414:105-111

17. Hou Y, Zou Q, Ge R, Shen F, Wang Y: The critical role of CD133(+) CD44(+/high) tumor cells in hematogenous metastasis of liver cancers. Cell Res 2012, 22:259-272

18. Jaggupilli A, Elkord E: Significance of CD44 and CD24 as cancer stem cell markers: an enduring ambiguity. Clin Dev Immunol 2012, 2012:708036

19. Salnikov AV, Kusumawidjaja G, Rausch V, Bruns H, Gross W, Khamidjanov A, Ryschich E, Gebhard MM, Moldenhauer G, Buchler MW, Schemmer P, Herr I: Cancer stem cell marker expression in hepatocellular carcinoma and liver metastases is not sufficient as single prognostic parameter. Cancer Lett 2009, 275: 185-193 
20. Clevers H: Modeling development and disease with organoids. Cell 2016, 165:1586-1597

21. Zhu L, Gibson P, Currle DS, Tong Y, Richardson RJ, Bayazitov IT, Poppleton H, Zakharenko S, Ellison DW, Gilbertson RJ: Prominin 1 marks intestinal stem cells that are susceptible to neoplastic transformation. Nature 2009, 457:603-607

22. Huch M, Dorrell C, Boj SF, van Es JH, Li VS, van de Wetering M, Sato T, Hamer K, Sasaki N, Finegold MJ, Haft A, Vries RG, Grompe M, Clevers H: In vitro expansion of single Lgr5+ liver stem cells induced by Wnt-driven regeneration. Nature 2013, 494: $247-250$

23. Li H, Durbin R: Fast and accurate short read alignment with BurrowsWheeler transform. Bioinformatics 2009, 25:1754-1760

24. Dobin A, Davis CA, Schlesinger F, Drenkow J, Zaleski C, Jha S, Batut P, Chaisson M, Gingeras TR: STAR: ultrafast universal RNAseq aligner. Bioinformatics 2013, 29:15-21

25. Chen IH, Xue L, Hsu CC, Paez JS, Pan L, Andaluz H, Wendt MK, Iliuk AB, Zhu JK, Tao WA: Phosphoproteins in extracellular vesicles as candidate markers for breast cancer. Proc Natl Acad Sci U S A 2017, 114:3175-3180

26. Cox J, Mann M: MaxQuant enables high peptide identification rates, individualized p.p.b.-range mass accuracies and proteome-wide protein quantification. Nat Biotechnol 2008, 26:1367-1372

27. Tyanova S, Temu T, Sinitcyn P, Carlson A, Hein MY, Geiger T, Mann M, Cox J: The Perseus computational platform for comprehensive analysis of (prote)omics data. Nat Methods 2016, 13: $731-740$

28. Yu G, Wang LG, Han Y, He QY: clusterProfiler: an R package for comparing biological themes among gene clusters. OMICS 2012, 16 : 284-287

29. Luo W, Brouwer C: Pathview: an R/Bioconductor package for pathway-based data integration and visualization. Bioinformatics 2013, 29:1830-1831

30. Kordes C, Sawitza I, Muller-Marbach A, Ale-Agha N, Keitel V, Klonowski-Stumpe H, Haussinger D: CD133+ hepatic stellate cells are progenitor cells. Biochem Biophys Res Commun 2007, 352: 410-417

31. Lee CW, Kuo WL, Yu MC, Chen TC, Tsai CN, Lee WC, Chen MF: The expression of cytokeratin 19 in lymph nodes was a poor prognostic factor for hepatocellular carcinoma after hepatic resection. World J Surg Oncol 2013, 11:136

32. Hu L, Lau SH, Tzang CH, Wen JM, Wang W, Xie D, Huang M, Wang Y, Wu MC, Huang JF, Zeng WF, Sham JS, Yang M, Guan XY: Association of Vimentin overexpression and hepatocellular carcinoma metastasis. Oncogene 2004, 23:298-302

33. Wan J, Wen D, Dong L, Tang J, Liu D, Liu Y, Tao Z, Gao D, Sun H, Cao Y, Fan J, Wu W: Establishment of monoclonal HCC cell lines with organ site-specific tropisms. BMC Cancer 2015, 15:678

34. Cui J, Dong BW, Liang P, Yu XL, Yu DJ: Effect of c-myc, Ki-67, MMP-2 and VEGF expression on prognosis of hepatocellular carcinoma patients undergoing tumor resection. World J Gastroenterol 2004, 10:1533-1536

35. Chiba T, Iwama A, Yokosuka O: Cancer stem cells in hepatocellular carcinoma: therapeutic implications based on stem cell biology. Hepatol Res 2016, 46:50-57

36. Rountree CB, Mishra L, Willenbring H: Stem cells in liver diseases and cancer: recent advances on the path to new therapies. Hepatology 2012, 55:298-306

37. Yamashita T, Ji J, Budhu A, Forgues M, Yang W, Wang HY, Jia H, Ye Q, Qin LX, Wauthier E, Reid LM, Minato H, Honda M, Kaneko S, Tang ZY, Wang XW: EpCAM-positive hepatocellular carcinoma cells are tumor-initiating cells with stem/progenitor cell features. Gastroenterology 2009, 136:1012-1024

38. Liu S, Li N, Yu X, Xiao X, Cheng K, Hu J, Wang J, Zhang D, Cheng S, Liu S: Expression of intercellular adhesion molecule 1 by hepatocellular carcinoma stem cells and circulating tumor cells Gastroenterology 2013, 144:1031-1041.e10
39. Liu C, Liu L, Chen X, Cheng J, Zhang H, Shen J, Shan J, Xu Y, Yang Z, Lai M, Qian C: Sox9 regulates self-renewal and tumorigenicity by promoting symmetrical cell division of cancer stem cells in hepatocellular carcinoma. Hepatology 2016, 64:117-129

40. Lee TK, Castilho A, Cheung VC, Tang KH, Ma S, Ng IO: CD24(+) liver tumor-initiating cells drive self-renewal and tumor initiation through STAT3-mediated NANOG regulation. Cell Stem Cell 2011, 9:50-63

41. Kuhlmann WD, Peschke P: Hepatic progenitor cells, stem cells, and AFP expression in models of liver injury. Int J Exp Pathol 2006, 87: 343-359

42. Haraguchi N, Ishii H, Mimori K, Tanaka F, Ohkuma M, Kim HM Akita H, Takiuchi D, Hatano H, Nagano H, Barnard GF, Doki Y, Mori M: CD13 is a therapeutic target in human liver cancer stem cells. J Clin Invest 2010, 120:3326-3339

43. Yang ZF, Ho DW, Ng MN, Lau CK, Yu WC, Ngai P, Chu PW, Lam CT, Poon RT, Fan ST: Significance of CD90+ cancer stem cells in human liver cancer. Cancer Cell 2008, 13:153-166

44. Yakaboski E, Jares A, Ma Y: Stem cell gene SALL4 in aggressive hepatocellular carcinoma: a cancer stem cell-specific target? Hepatology 2014, 60:419-421

45. Wang B, Zhao L, Fish M, Logan CY, Nusse R: Self-renewing diploid Axin2(+) cells fuel homeostatic renewal of the liver. Nature 2015 $524: 180-185$

46. Huch M, Gehart $H$, van Boxtel R, Hamer K, Blokzijl F, Verstegen MM, Ellis E, van Wenum M, Fuchs SA, de Ligt J, van de Wetering M, Sasaki N, Boers SJ, Kemperman H, de Jonge J, Ijzermans JN, Nieuwenhuis EE, Hoekstra R, Strom S, Vries RR, van der Laan LJ, Cuppen E, Clevers H: Long-term culture of genomestable bipotent stem cells from adult human liver. Cell 2015, 160: 299-312

47. Merino-Azpitarte M, Lozano E, Perugorria MJ, Esparza-Baquer A, Erice O, Santos-Laso A, O’Rourke CJ, Andersen JB, JimenezAguero R, Lacasta A, D'Amato M, Briz O, Jalan-Sakrikar N, Huebert RC, Thelen KM, Gradilone SA, Aransay AM, Lavin JL, Fernandez-Barrena MG, Matheu A, Marzioni M, Gores GJ, Bujanda L, Marin JJG, Banales JM: SOX17 regulates cholangiocyte differentiation and acts as a tumor suppressor in cholangiocarcinoma. J Hepatol 2017, 67:72-83

48. Jia Y, Yang Y, Liu S, Herman JG, Lu F, Guo M: SOX17 antagonizes WNT/beta-catenin signaling pathway in hepatocellular carcinoma. Epigenetics 2010, 5:743-749

49. Polakis P: Wnt signaling and cancer. Genes Dev 2000, 14 $1837-1851$

50. Xu MZ, Yao TJ, Lee NP, Ng IO, Chan YT, Zender L, Lowe SW Poon RT, Luk JM: Yes-associated protein is an independent prognostic marker in hepatocellular carcinoma. Cancer 2009, 115 4576-4585

51. Schmitz KJ, Wohlschlaeger J, Lang H, Sotiropoulos GC, Malago M, Steveling K, Reis H, Cicinnati VR, Schmid KW, Baba HA: Activation of the ERK and AKT signalling pathway predicts poor prognosis in hepatocellular carcinoma and ERK activation in cancer tissue is associated with hepatitis C virus infection. J Hepatol 2008, 48:83-90

52. Breuhahn K, Longerich T, Schirmacher P: Dysregulation of growth factor signaling in human hepatocellular carcinoma. Oncogene 2006 $25: 3787-3800$

53. Okumoto K, Hattori E, Tamura K, Kiso S, Watanabe H, Saito K Saito T, Togashi H, Kawata S: Possible contribution of circulating transforming growth factor-betal to immunity and prognosis in unresectable hepatocellular carcinoma. Liver Int 2004, 24:21-28

54. Zender S, Nickeleit I, Wuestefeld T, Sorensen I, Dauch D, Bozko P, El-Khatib M, Geffers R, Bektas H, Manns MP, Gossler A, Wilkens L, Plentz R, Zender L, Malek NP: A critical role for notch signaling in the formation of cholangiocellular carcinomas. Cancer Cell 2013, 23: 784-795

55. Zhao J, Dong L, Lu B, Wu G, Xu D, Chen J, Li K, Tong X, Dai J, Yao S, Wu M, Guo Y: Down-regulation of osteopontin suppresses 
growth and metastasis of hepatocellular carcinoma via induction of apoptosis. Gastroenterology 2008, 135:956-968

56. Gupta BK, Maher DM, Ebeling MC, Sundram V, Koch MD, Lynch DW, Bohlmeyer T, Watanabe A, Aburatani H, Puumala SE, Jaggi M, Chauhan SC: Increased expression and aberrant localization of mucin 13 in metastatic colon cancer. J Histochem Cytochem 2012, 60:822-831

57. Yap LF, Jenei V, Robinson CM, Moutasim K, Benn TM, Threadgold SP, Lopes V, Wei W, Thomas GJ, Paterson IC: Upregulation of Eps8 in oral squamous cell carcinoma promotes cell migration and invasion through integrin-dependent Rac1 activation. Oncogene 2009, 28:2524-2534

58. Steele CW, Karim SA, Leach JD, Bailey P, Upstill-Goddard R, Rishi L, Foth M, Bryson S, McDaid K, Wilson Z, Eberlein C, Candido JB, Clarke M, Nixon C, Connelly J, Jamieson N, Carter CR, Balkwill F, Chang DK, Evans TR, Strathdee D, Biankin AV, Nibbs RJ, Barry ST, Sansom OJ, Morton JP: CXCR2 inhibition profoundly suppresses metastases and augments immunotherapy in pancreatic ductal adenocarcinoma. Cancer Cell 2016, 29:832-845

59. Chao A, Tsai CL, Jung SM, Chuang WC, Kao C, Hsu A, Chen SH, Lin CY, Lee YC, Lee YS, Wang TH, Wang HS, Lai CH: BAI1associated protein 2-like 1 (BAIAP2L1) is a potential biomarker in ovarian cancer. PLoS One 2015, 10:e0133081

60. Shang S, Plymoth A, Ge S, Feng Z, Rosen HR, Sangrajrang S, Hainaut P, Marrero JA, Beretta L: Identification of osteopontin as a novel marker for early hepatocellular carcinoma. Hepatology 2012, 55:483-490

61. Fan B, Malato Y, Calvisi DF, Naqvi S, Razumilava N, Ribback S, Gores GJ, Dombrowski F, Evert M, Chen X, Willenbring H: Cholangiocarcinomas can originate from hepatocytes in mice. J Clin Invest 2012, 122:2911-2915

62. Sekiya S, Suzuki A: Intrahepatic cholangiocarcinoma can arise from Notch-mediated conversion of hepatocytes. J Clin Invest 2012, 122: 3914-3918

63. Holczbauer A, Factor VM, Andersen JB, Marquardt JU, Kleiner DE, Raggi C, Kitade M, Seo D, Akita H, Durkin ME, Thorgeirsson SS: Modeling pathogenesis of primary liver cancer in lineage-specific mouse cell types. Gastroenterology 2013, 145:221-231

64. Andersen JB, Loi R, Perra A, Factor VM, Ledda-Columbano GM, Columbano A, Thorgeirsson SS: Progenitor-derived hepatocellular carcinoma model in the rat. Hepatology 2010, 51:1401-1409

65. Kowalik MA, Sulas P, Ledda-Columbano GM, Giordano S, Columbano A, Perra A: Cytokeratin-19 positivity is acquired along cancer progression and does not predict cell origin in rat hepatocarcinogenesis. Oncotarget 2015, 6:38749-38763

66. Boulter L, Guest RV, Kendall TJ, Wilson DH, Wojtacha D, Robson AJ, Ridgway RA, Samuel K, Van Rooijen N, Barry ST, Wigmore SJ, Sansom OJ, Forbes SJ: WNT signaling drives cholangiocarcinoma growth and can be pharmacologically inhibited. J Clin Invest 2015, 125:1269-1285

67. Razumilava N, Gores GJ: Cholangiocarcinoma. Lancet 2014, 383 : $2168-2179$

68. Sugimachi K, Nishio M, Aishima S, Kuroda Y, Iguchi T, Komatsu H, Hirata H, Sakimura S, Eguchi H, Bekki Y, Takenaka K, Maehara Y, Suzuki A, Mimori K: Altered expression of Hippo signaling pathway molecules in intrahepatic cholangiocarcinoma. Oncology 2017, 93:67-74

69. Calderaro J, Couchy G, Imbeaud S, Amaddeo G, Letouze E, Blanc JF, Laurent C, Hajji Y, Azoulay D, Bioulac-Sage P, Nault JC,
Zucman-Rossi J: Histological subtypes of hepatocellular carcinoma are related to gene mutations and molecular tumour classification. J Hepatol 2017, 67:727-738

70. Cancer Genome Atlas Resource Network: Comprehensive and integrative genomic characterization of hepatocellular carcinoma. Cell 2017, 169:1327-1341.e23

71. Celia-Terrassa T, Kang Y: Distinctive properties of metastasisinitiating cells. Genes Dev 2016, 30:892-908

72. Herreros-Villanueva M, Bujanda L: Glypican-1 in exosomes as biomarker for early detection of pancreatic cancer. Ann Transl Med 2016, 4:64

73. Simpson RJ, Lim JW, Moritz RL, Mathivanan S: Exosomes: proteomic insights and diagnostic potential. Expert Rev Proteomics 2009, 6:267-283

74. Kahlert C, Kalluri R: Exosomes in tumor microenvironment influence cancer progression and metastasis. J Mol Med (Berl) 2013, 91: 431-437

75. Arbelaiz A, Azkargorta M, Krawczyk M, Santos-Laso A, Lapitz A, Perugorria MJ, Erice O, Gonzalez E, Jimenez-Aguero R, Lacasta A, Ibarra C, Sanchez-Campos A, Jimeno JP, Lammert F, Milkiewicz P, Marzioni M, Macias RIR, Marin JJG, Patel T, Gores GJ, Martinez I, Elortza F, Falcon-Perez JM, Bujanda L, Banales JM: Serum extracellular vesicles contain protein biomarkers for primary sclerosing cholangitis and cholangiocarcinoma. Hepatology 2017, 66: $1125-1143$

76. Julich-Haertel H, Urban SK, Krawczyk M, Willms A, Jankowski K, Patkowski W, Kruk B, Krasnodebski M, Ligocka J, Schwab R, Richardsen I, Schaaf S, Klein A, Gehlert S, Sanger H, Casper M, Banales JM, Schuppan D, Milkiewicz P, Lammert F, Krawczyk M, Lukacs-Kornek V, Kornek M: Cancer-associated circulating large extracellular vesicles in cholangiocarcinoma and hepatocellular carcinoma. J Hepatol 2017, 67:282-292

77. Wang YP, Huang LY, Sun WM, Zhang ZZ, Fang JZ, Wei BF, Wu BH, Han ZG: Insulin receptor tyrosine kinase substrate activates EGFR/ERK signalling pathway and promotes cell proliferation of hepatocellular carcinoma. Cancer Lett 2013, 337:96-106

78. Higashiyama M, Okami J, Maeda J, Tokunaga T, Fujiwara A, Kodama K, Imamura F, Kobayashi H: Differences in chemosensitivity between primary and paired metastatic lung cancer tissues: in vitro analysis based on the collagen gel droplet embedded culture drug test (CD-DST). J Thorac Dis 2012, 4:40-47

79. Kern DH: Heterogeneity of drug resistance in human breast and ovarian cancers. Cancer J Sci Am 1998, 4:41-45

80. Villanueva A, Llovet JM: Second-line therapies in hepatocellular carcinoma: emergence of resistance to sorafenib. Clin Cancer Res 2012, 18:1824-1826

81. Rodon J, Dienstmann R, Serra V, Tabernero J: Development of PI3K inhibitors: lessons learned from early clinical trials. Nat Rev Clin Oncol 2013, 10:143-153

82. Howes AL, Chiang GG, Lang ES, Ho CB, Powis G, Vuori K, Abraham RT: The phosphatidylinositol 3-kinase inhibitor, PX-866, is a potent inhibitor of cancer cell motility and growth in threedimensional cultures. Mol Cancer Ther 2007, 6:2505-2514

83. Falkenberg N, Hofig I, Rosemann M, Szumielewski J, Richter S, Schorpp K, Hadian K, Aubele M, Atkinson MJ, Anastasov N: Threedimensional microtissues essentially contribute to preclinical validations of therapeutic targets in breast cancer. Cancer Med 2016, 5: $703-710$ 